\title{
Allende, el allendismo y los partidos: El Frente de Acción Popular ante las elecciones presidenciales de 1958
}

\section{Allende, the Allendism and the political parties: The Popular Action Front and the 1958's presidential elections}

\begin{abstract}
Resumen
Mediante el análisis de prensa informativa y partidaria, documentos partidistas, textos de memorialistas y estadística electoral, analizaremos la relación establecida entre Salvador Allende y los partidos Comunista y Socialista en las elecciones de presidenciales de 1958. Al respecto, sostendremos que dicha elección fue el acontecimiento que dejó en evidencia el surgimiento del allendismo, en cuanto una fuerza política capaz de movilizar a un electorado mayor que el de los partidos políticos de izquierda y generar lealtades políticas al interior de estos mismos.
\end{abstract}

Palabras Clave: Allendismo - Salvador Allende - Partidos Políticos Partido Comunista - Partido Socialista - Frente de Acción Popular Elecciones

\begin{abstract}
By analyzing informative and partisan press, party documents, books of memories and electoral statistics, we will analyze the relationship established between Salvador Allende and the Communist and Socialist parties in the 1958's presidential elections. In this regard, we will argue that this election was the event which revealed the emergence of the Allendism, as a political force capable of mobilizing an electorate greater than the one of the leftist political parties and generate political loyalties within them.
\end{abstract}

Key Words: Allendism- Salvador Allende- Political Parties- Socialist Party -Communist Party - Popular Action Front -Elections

\footnotetext{
* Chileno. Ph. D ( ) Leiden University. Profesor Investigador CIDOC-Escuela de Historia, Universidad Finis Terrae. E-mail: jfernandez@uft.cl
} 


\section{Introducción}

Existe un importante consenso en la historiografía política chilena al momento de tratar las elecciones presidenciales de 1958. Se ha sostenido que dichos comicios habrían evidenciado el surgimiento de la política de los tres tercios, el comienzo del ascenso del Partido Demócrata Cristiano y la crisis del centro radical'. De manera más específica, al momento de tratar la candidatura de Salvador Allende, el corpus bibliográfico muestra dos orientaciones principales. La primera tiende a observarla desde el punto de vista del candidato, adoptando un prisma biográfico, y la segunda a analizarla desde el punto de vista de las estrategias políticas de los partidos de izquierda y sus polémicas².

$\mathrm{Al}$ respecto, creemos necesario profundizar en el estudio de la relación entre Salvador Allende y los partidos políticos y tener en cuenta la importancia del allendismo en cuanto fuerza política.

La mayor parte de los estudios politológicos e historiográficos referidos a la historia contemporánea chilena han tendido a resaltar la importancia del rol jugado por los partidos políticos en ella. Como ha sostenido J. Samuel Valenzuela

Los partidos políticos han sido organizaciones claves en el desarrollo y funcionamiento de la democracia en Chile. Ya sea al establecer los parámetros del debate político, estructurar las opciones electorales, articular los intereses sociales, formar y proyectar nacionalmente los liderazgos políticos, constituir los gobiernos y organizar el proceso legislativo ${ }^{3}$.

Coincidiendo con dicho planteamiento en términos generales, creemos necesario matizarlo y complejizarlo, teniendo en cuenta como los partidos debieron convivir y negociar con fuerzas políticas generadas en torno a liderazgos carismáticos y adhesiones personales. Por lo demás, al estudiar al Allendismo nos aproximamos una forma de adhesión política que se proyectó en el tiempo, incluso más allá de la muerte del propio Salvador Allende,

\footnotetext{
${ }^{1}$ Entre los trabajos que abordan de manera general las elecciones de 1958 se encuentran los de Isabel Torres Dujisin, La crisis del sistema democrático: Las elecciones presidenciales y los proyectos políticos excluyentes. Chile-1958-1970 (Santiago: Centro de Investigaciones Diego Barros Arana- Editorial Universitaria, 2014) y Patricia Arancibia, "La elección presidencial de 1958. Jorge Alessandri y la derecha a la Moneda", Alejandro San Francisco y Ángel Soto, Camino a la Moneda. Las elecciones presidenciales en la historia de Chile (Santiago: Instituto de Historia PUC- Bicentenario, 2005).

${ }^{2}$ En la perspectiva biográfica, los trabajos más acabados corresponden a los de Diana Veneros, Allende. Un ensayo psicobiográfico (Santiago: Random House Mondadori, 2003) y Mario Amorós, Allende. La Biografía (Santiago: Ediciones B, 2013) desde el punto de vista de la izquierda partidista en su conjunto destacan las obras de Julio Faúndez, Izquierdas y democracia en Chile, 1932-1973 (Santiago: Bat, 1992) y Marcelo Casals Araya, El Alba de Una Revolución. La Izquierda y el proceso de Construcción Estratégica de la "Vía Chilena al Socialismo”. 1956-1970 (Santiago: Lom, 2010).

${ }^{3}$ J. Samuel Valenzuela, "Orígenes y transformaciones del sistema de partidos en Chile”, Estudios Públicos 58. Santiago (1995) 6.
} 
transformando a este último en un símbolo y referente identitario entre importantes sectores de la izquierda chilena.

A través de este artículo analizaremos la relación establecida entre Salvador Allende y los partidos Comunista y Socialista en las elecciones presidenciales de 1958. Al respecto, sostendremos que dicha elección fue el acontecimiento que dejó en evidencia el surgimiento del allendismo, en cuanto una fuerza política relevante. Dicha fuerza se habría caracterizado por la capacidad de movilizar a un electorado que rebasaba a los partidos de izquierda, y la habilidad para generar lealtades políticas al interior de estos mismos, por sobre los vínculos de carácter partidista-institucional. Si bien las adhesiones, tanto militantes como electorales, al allendismo habrían tenido un carácter carismático, el liderazgo político de Allende demostró una alta valoración de la política institucionalizada, evitando generar un liderazgo político caudillista y colaborando en la articulación de partidos políticos con líneas estratégicas disímiles, como eran el Partido Comunista (PC) y el Partido Socialista (PS).

Para lograr este objetivo, hemos realizado un texto que se encuentra dividido en seis secciones. En primer lugar abordaremos la política coalicional de los partidos de izquierda entre los años 1952 y 1958. Trataremos el proceso de unificación de la izquierda, expresado en la formación del Frente de Acción Popular y la reunificación del Partido Socialista, centrándonos en como éste se vio tensionado por las diferencias entre comunistas y socialistas con respecto a las líneas estratégicas a seguir. En segundo lugar, abordaremos el debate generado al interior de los partidos Comunista y Socialista sobre la elección del candidato presidencial y cómo la figura de Salvador Allende se insertó en dicha discusión. En tercer lugar, trataremos la "Convención Presidencial del Pueblo", instancia en que Salvador Allende fue elegido candidato presidencial. Al tratarla, caracterizaremos a los participantes de la convención y describiremos los complejos mecanismos diseñados para elegir candidato, analizando los motivos que llevaron a adoptar dichos procedimientos y el modo en que se llevaron a la práctica. En cuarto lugar analizaremos el programa de gobierno de la candidatura de Salvador Allende. Sintetizaremos sus principales medidas, identificaremos a los artífices de sus medidas económicas y algunas de las experiencias e ideas que confluyeron en su conformación. En quinto lugar, abordaremos el desarrollo de la campaña presidencial. Consideraremos en cuanto contexto, la situación social del país, y los radicales cambios a las reglas del juego político que se generaron debido a la acción del Bloque de Saneamiento Democrático. Pondremos énfasis al tratar las estrategias propagandísticas de la izquierda y la actuación del propio Salvador Allende. Finalmente, y en sexto lugar, realizaremos un análisis sobre el desempeño electoral de Salvador Allende en las Elecciones de 1958, teniendo en cuenta variables de clase social, género y región, adoptando una perspectiva comparativa con respecto a las elecciones de 1952

Para lograr nuestros objetivos, recurriremos a un corpus de fuentes primarias de diverso tipo. Utilizaremos fuentes hemerográficas, principalmente revistas noticiosas para obtener información y descripciones de los acontecimientos estudiados, al mismo tiempo que declaraciones de sus actores. También revisaremos prensa, folletos y documentos partidistas, con el objeto de obtener declaraciones oficiales de los partidos. Con el fin de conocer algunos aspectos de la discusión interna de los partidos y de las percepciones de los 
actores involucrados, difícilmente abordables con la información pública disponible en la época, hemos recurrido al uso de memorias y entrevistas. Estas fuentes serán contrastadas con la información aportada por las fuentes escritas. Finalmente utilizaremos estadísticas electorales, destinadas a conocer el desempeño de la candidatura en diversos ámbitos.

\section{La política coalicional de la izquierda y sus perspectivas electorales hacia mediados de la década de 1950}

La candidatura de Salvador Allende en la elección presidencial de 1958 está inscrita en el proceso de unificación y definición de líneas estratégicas que vivieron los partidos políticos de izquierda en la década de 1950.

Inmediatamente después de las elecciones de 1952, el Frente del Pueblo, coalición que había apoyado a Salvador Allende en las elecciones presidenciales de 1952 y que estaba compuesta por el Partido Socialista de Chile y el Partido Comunista en la clandestinidad, comenzó a desarrollar un lento proceso de acercamiento hacia fuerzas menores de centroizquierda. La coalición, que hacia 1953 pasó a denominarse Frente Nacional del Pueblo (FREnAP), incluyó en dicho año al Partido Democrático y en 1954 al Partido del Trabajo. Estas alianzas permitieron que la presencia en el Congreso de la izquierda unida en el FRENAP creciera levemente a expensas del centrismo radical y del populismo ibañista. Es necesario tener en cuenta que el Partido Democrático, junto con las fuerzas socialcristianas y falangistas, había apoyado al abanderado radical Pedro Enrique Alfonso en las elecciones de 1952. Por su parte, el Partido del Trabajo era dirigido por el escritor Baltazar Castro, quien en 1952 había abandonado el Partido Socialista Popular para unirse a la acción de los movimientos ibañistas independientes. Castro, en su colectividad, había reunido a una heterogénea combinación que incluía, entre otros, a ibañistas de izquierda y comunistas en la clandestinidad. Estos últimos veían en el partido una suerte de organización instrumental, que facilitaba su actividad política en el marco de la proscripción ${ }^{4}$.

El crecimiento del FRENAP, por otro lado, muestra como dicha coalición actuaba bajo los criterios derivados de la estrategia de Frente de Liberación Nacional del Partido Comunista, los que a su vez eran coincidentes con los afanes del allendismo ${ }^{5}$. Estas fuerzas

\footnotetext{
"Para un recuento de los hitos del proceso de unificación de la izquierda, véase "Unificación socialista", Principios 43 [Santiago], julio-agosto de 1957. Sobre el Partido del Trabajo y sus vínculos con el Partido Comunista chileno, véase Entrevista a José Cademártori. Santiago. 11 de agosto de 2010. Archivo CIDOCUniversidad Finis Terrae. Sobre los debates al interior de la izquierda chilena en el período véase Pablo Rubio Apiolaza, "La izquierda chilena en la década de 1950: Socialistas, comunistas y sus contradicciones" y Luis Ortega Martínez, "Del Frente de Trabajadores al Congreso de Chillán. Los Socialistas de Chile entre 1956 y 1967”, Revista Electrónica Palimpsesto 1. 1. Santiago (2003)

${ }_{5}^{5}$ Casals 21-29. La Línea Estratégica del Frente de Liberación Nacional, proclamada por el Partido Comunista de Chile en su Conferencia Nacional de agosto de 1952, proponía la generación de alianzas amplias, que incluyeran a sectores de la burguesía nacional progresista y sus expresiones partidistas, los partidos reformistas de centro, en pos de un programa de profundas transformaciones estructurales, de contenido antimperialista y antioliárquico. A diferencia de líneas estratégicas anteriores, que también habían propugnado alianzas amplias,
} 
pensaban reforzar la hegemonía de un núcleo conformado por los partidos de los trabajadores, abriéndose hacia el centro para captar las adhesiones de partidos reformistas. En todo caso, el problema de la vinculación con el Partido Radical continuaba siendo incómodo para el FRENAP. A las desconfianzas generadas por la política represiva y errática de Gabriel González Videla, se sumaba el hecho de que el peso electoral de dicho partido hacía inviables los afanes hegemónicos de los partidos de izquierda. Esto volvía imposible el objetivo de generar una alianza en que los sectores "burgueses", representados en el radicalismo, reconocieran la primacía de los partidos de la izquierda. A pesar de este problema, el FRENAP realizó alianzas circunstanciales con distintas fuerzas políticas, destinadas a oponerse al gobierno de Ibáñez en el marco de la acción legislativa y de elecciones complementarias ${ }^{6}$.

Sin embargo, el gran problema para las aspiraciones del FRENAP seguía siendo la imposibilidad de concretar la unidad de los partidos de izquierda. Esto debido a que el Partido Socialista Popular, con el triunfo de Carlos Ibáñez en 1952, había pasado a formar parte del Gobierno. Esta situación, en un comienzo, trajo importantes réditos electorales a los socialistas populares, quienes, en las elecciones parlamentarias de 1953, alcanzaron un $8,3 \%$ de los votos, incrementando en un 3,5\% su votación. Mientras tanto, el Partido Socialista de Allende obtuvo apenas un 1,5\% de los votos ${ }^{7}$. A pesar de ello, las fuerzas del FRENAP, y especialmente los comunistas, hicieron reiterados llamados a los socialistas populares para que abandonaran al ibañismo y se unieran a su alianza. Las esperanzas del FRENAP se acrecentaron cuando los socialistas abandonaron el gobierno de Ibáñez en octubre de 1953 a un año de haber triunfado, decepcionados con Ibáñez tras la aplicación de medidas represivas a movimientos huelguísticos y la mantención de los convenios militares

como fue el caso del Frente Popular y de la Unidad Nacional Antifascista, en el caso del Frente de Liberación Nacional se sostenía que la hegemonía al interior de la alianza debía recaer en los "partidos de la clase obrera", es decir, socialistas y comunistas. Véase Carmelo Furci, El Parido Comunista de Chile y la vía al Socialismo (Santiago: Ariadna, 2008) 85 y 86. Al respecto también es necesario tener en cuenta las transformaciones sufridas por los referentes ideológicos internacionales del comunismo chileno. El proceso de desestalinización, que comenzó en el año 1956 en la URSS reforzó las tendencias que ya habían sido marcadas por la estrategia del Frente de Liberación Nacional. Como ha sostenido Alfredo Riquelme, dicho ambiente habría propiciado que el Partido Comunista asumiera "con gran convicción en el ámbito nacional la construcción de una vía pacífica, democrática, semejante las vías nacionales que en esos mismos años imaginaban los comunistas en países de Europa occidental como Italia”. Dicha situación facilitaba los acercamientos a un Partido Socialista que mantenía fuertes críticas al modelo soviético. Véase Alfredo Riquelme Segovia, "La Guerra Fría en Chile: Los intrincados nexos entre lo nacional y lo Global”, Tanya Harmer y Alfredo Riquelme Segovia (Editores), Chile y la Guerra Fría Global (Santiago: Instituto de Historia de la Pontificia Universidad Católica de Chile RIL Editores, 2014) 14-15.

${ }^{6}$ Cecilia Riveros Romero, Salvador Allende: Un líder para la izquierda chilena. Prólogo para un epílogo. Tesis para optar al Grado de Licenciado en Historia (Santiago: Pontificia Universidad Católica de Chile, 2006)

'Germán Urzúa Valenzuela, Historia política de Chile y su evolución electoral. (Desde 1810 a 1992). (Santiago: Editorial Jurídica de Chile, 1992) 567 
con los Estados Unidos. Después de esta situación, los llamados del FRENAP a la unidad se redoblaron, aunque sin mayores resultados ${ }^{8}$.

En todo caso, y pese a las reticencias de las cúpulas partidistas, las tendencias a la unificación de la izquierda comenzaron a hacerse manifiestas en las bases sindicales. En 1953 surgió la Central Única de Trabajadores (CUT) organización que volvió a agrupar al sindicalismo chileno, incluyendo a socialistas y comunistas, las dos corrientes políticas que más importancia tenían en dicho movimiento social. Por lo demás, los sindicatos socialistas y comunistas comenzaron a realizar con cada vez mayor frecuencia acciones comunes contra un gobierno que había reforzado la represión al movimiento obrero, en aras de implementar una política antiinflacionaria que apuntaba a controlar las demandas sociales. El contexto político económico del país coadyuvó a acelerar las tendencias a la unificación. Hacia fines del año 1955 creció el descontento social en medio de una crisis inflacionaria. El gobierno realizó un viraje a la derecha, y se hizo inminente la implementación de las políticas monetaristas ortodoxas y liberalizadoras recomendadas por parte de la misión Klein-Sacks, respaldadas por Estados Unidos y el Fondo Monetario Internacional ${ }^{9}$.

No es de extrañar que esta situación reforzara la desconfianza hacia el centro político que ya venía profesando el Partido Socialista Popular. En octubre de 1955, en el marco de su XVI Congreso, el Partido Socialista Popular lanzó su línea estratégica denominada Frente de Trabajadores. En ella declararon agotadas las alianzas con los "partidos burgueses", sosteniendo que la burguesía era incapaz de generar reformas democráticas. Por lo mismo, los socialistas sostuvieron que no existían dos "etapas" en la revolución, -una democrático burguesa y otra socialista, como planteaban los comunistas. Por el contrario, para el Partido Socialista Popular "la revolución socialista pasaba a ser un "proceso ininterrumpido, liderado desde un comienzo por la clase trabajadora" ${ }^{10}$. En la práctica, esto significaba que los socialistas populares pasarían a propugnar la necesidad de formar un gran frente entre los partidos que representaban a los trabajadores, como eran socialistas y comunistas, y al mismo tiempo, desarrollarían una oposición tajante al establecimiento de alianzas con radicales o falangistas.

En este marco, se desarrollaron conversaciones entre el Partido Socialista Popular, el Partido Democrático del Pueblo y el Frenap, que desembocaron en la formación del Frente de Acción Popular (FRAP), el 29 de febrero de 1956, reuniendo en sus filas a los partidos Comunista de Chile, Socialista Popular, Socialista de Chile, Democrático del Pueblo, Democrático y del Trabajo. El FRAP, desde sus inicios, renegó de la posibilidad de entablar alianzas con los partidos "burgueses", al mismo tiempo que desarrolló un programa de reformas sociales profundas, pero que no aspiraban a la creación inmediata de una sociedad

\footnotetext{
${ }^{8}$ Juan Hernández, "Desarrollemos el Frente de Liberación Nacional”, Principios 21 [Santiago], noviembrediciembre de 1953 y Raúl Ampuero, La izquierda en punto muerto (Santiago: Orbe, 1969) 54-55

${ }^{9}$ Faúndez 112-114 y 124. Sobre la actitud de la izquierda chilena ante la misión Klein \& Saks y la movilización generada en su contra véase Pedro Simunovic, Identidad y antiimperialismo en la izquierda: el caso de la Misión Klein - Saks”. Tesis para optar al grado de Licenciado en Historia (Santiago: Universidad Alberto Hurtado, 2013)

${ }^{10}$ Faúndez 166
} 
socialista. En este sentido, la línea estratégica del FRAP puede considerarse como el resultado "híbrido" de la política de alianzas propia del Frente de Trabajadores, con la plataforma programática del Frente de Liberación Nacional ${ }^{11}$.

Las fuerzas del FRAP se presentaron juntas a las elecciones parlamentarias de marzo de 1957, obteniendo cerca de un 22\% de los votos, reflejando una situación de relativo estancamiento en relación a los resultados obtenidos por las fuerzas que los componían en $1953^{12}$. Tras esta situación, por otro lado, se produjo la reunificación del socialismo. Entre el 5 y 7 de julio de 1957 tuvo lugar el XVII Congreso del Partido Socialista, que fusionó a los Partidos Socialista de Chile y Socialista Popular. El Congreso eligió como Secretario General a Salomón Corbalán y reforzó la línea de Frente de Trabajadores ${ }^{13}$.

$\mathrm{Al}$ respecto, las resoluciones del Congreso fueron elocuentes:

[el] crecimiento demasiado rápido [del partido] y su falta de madurez ideológica y orgánica, frustraron las esperanzas que las masas habían cifrado en el. La falta de una elaboración crítica de la política del PARTIDO, que debió afincarse en un auténtico análisis de la realidad chilena, por una parte, y la ausencia de una firme convicción revolucionaria por otra, dieron origen a tendencias infantilistas y oportunistas que lo anarquizaron orgánica e ideológicamente.

Ha sido necesario que el socialismo chileno hiciera esta triste experiencia de varios años para que se crearan las condiciones objetivas y subjetivas para una superación ideológica y para una acción práctica consecuente que condujera a la unificación del socialismo en un más alto nivel.

[...]La debilidad e incapacidad de la clase media, sus partidos y su ideología individualista, para continuar el proceso social chileno, debido a su tendencia a capitular frente al imperialismo y a la reacción, comprometiéndose con ellos en el aprovechamiento y la defensa del orden establecido

De las consideraciones anteriores se desprende que un sólo y vasto FRENTE DE TRABAJADORES, manuales e intelectuales, bajo el comando y la hegemonía de la clase obrera e inspirada en la ideología socialista, puede ser capaz de alterar el "statu quo" nacional, proponiéndose abiertamente la toma del poder como único medio para realizar consecuentemente sus aspiraciones ${ }^{14}$.

Las resoluciones del XVII Congreso fueron un triunfo del sector ampuerista, proveniente del Partido Socialista Popular y un revés temporal para la postura de los socialistas de chile y el allendismo, pues estos últimos eran partidarios de buscar alianzas con los radicales. Como expresara el periodista Luis Hernández Parker:

\footnotetext{
${ }^{11}$ Jorge Arrate y Eduardo Rojas, Memoria de la Izquierda Chilena. Tomo I (1850-1970) (Santiago: Vergara, 2003) 308

${ }^{12}$ Urzúa 579

${ }^{13}$ Julio Cesar Jobet, Historia de Partido Socialista de Chile (Santiago: Documentas, 1987) 226-239

${ }^{14}$ "Un nuevo camino para el socialismo chileno". Boletín del Comité Central del PS 1 [Santiago] julio-agosto de $1957: 1,3$ y 6
} 
El asunto más discrepante está en la actitud frente a la pugna presidencial. Dentro del FRAP, los comunistas, democráticos, Partido del Trabajo y en parte el antiguo Partido Socialista de Allende creen que se debe trazar una línea que le permita al FRAP jugar un rol decisivo en septiembre de 1958. Para ellos, no se pueden aprobar votos de un infantilismo revolucionario sino realistas. Estos grupos en el fondo quieren encontrar tal definición presidencial que obligue al Partido Radical a entrar en negociaciones con el FRAP o a aliarse definitivamente con la Derecha [...] en cambio los socialistas (y dentro de ellos los ampueristas) prefieren al diablo antes que a una candidatura radical. Son tan sañudamente anti radicales como un sector de los radicales es enconadamente anti-ampuerista. Están pagados ${ }^{15}$.

De este modo, la unidad coalicional de comunistas y socialistas se consolidaba con miras a las elecciones de 1958. Sin embargo, dicha unidad estuvo marcada por las discrepancias estratégicas, las que se notaron en las discusiones sobre el modo de enfrentar las elecciones presidenciales que advenían. Fue este el marco en que se gestó la candidatura presidencial de Salvador Allende y que condicionó muchas de sus características.

\section{Salvador Allende y los partidos del FRAP}

La elección de Allende como precandidato presidencial por parte de socialistas y comunistas fue compleja. En un comienzo, el propio Salvador Allende se mostró reticente a asumir el reto. Según su percepción, "no estaban dadas las condiciones para [el triunfo] de un candidato socialista-comunista" ${ }^{16}$. La unidad de la izquierda era un hecho reciente, y Allende percibía que aún no existía la claridad programática para gobernar. Por lo demás, la fuerza electoral de la izquierda unida no aparecía como suficiente para ganar una elección y menos para sostener un gobierno. A las aprehensiones personales de Allende, se sumaba el hecho que en su propio partido existían importantes sectores que se mostraban contrarios a su figura. Allende generaba un fuerte rechazo en los sectores “ampueristas”, provenientes del Partido Socialista Popular, que habían apoyado a Ibáñez en 1952. Dichas facciones consideraban que Allende había actuado de manera personalista y que representaba un tipo de político de viejo cuño, de sospechosas tendencias reformistas y desviaciones liberales y pequeño-burgueses ${ }^{17}$. Como recordara años después Erich Schnake, adscrito en ese entonces a dichos sectores:

\footnotetext{
${ }^{15}$ “6 de julio de 1957. Panorama presidencial para 1958. Se unifican socialistas y nace la Democracia Cristiana”. Luis Hernández Parker, Señores auditores: muy buenas tardes (Comentarios políticos). Selección de Pamela Hernández y Silvia Hernández (Santiago: Lom Ediciones, 2010) 105-108

${ }^{16}$ Entrevista a José Cademártori. Santiago. 11 de agosto de 2010. Archivo CIDOC-Universidad Finis Terrae. Cademártori recuerda que Allende habría manifestado esta posición en diversas reuniones que sostuvo junto a otros personeros del FRAP en su casa de calle Guardia Vieja.

${ }^{17}$ Diana Veneros, Allende. Un ensayo psicobiográfico (Santiago: Random House Mondadori, 2003$) 217$ 218.Una Justificación de la línea de acción política del PSP y una crítica a la actuación de Salvador Allende puede ser encontrada en Oscar Waiss, Nacionalismo y Socialismo en América Latina (Santiago: Prensa Latinoamericana, 1954) 103-154
} 
El centro político que representaba el Partido Radical había que conquistarlo con una política revolucionaria; la pequeña burguesía era una clase oscilante a la que había que conquistar desde posiciones de poder [...] Ampuero, Aniceto Rodríguez, Almeyda, Oscar Waiss y todo el PSP, prácticamente, lideraban esta posición. Allende, Carlos Briones, Manuel Mandujano, Armando Mallet, José Tohá, Agustín Álvarez Villablanca, y otros, calificados por nosotros como 'pequeño burgueses reformistas', sostenían la contraria. ${ }^{18}$

En la dirección del Partido Comunista, si bien había una mejor apreciación de la figura de Allende, coincidían en el diagnóstico sobre la falta de preparación de la izquierda y sus escasas posibilidades de triunfar. Junto con mostrarse escépticos ante la eventualidad de una victoria, creían, siguiendo los lineamientos de la estrategia del Frente de Liberación Nacional y las resoluciones del XXIV Pleno del Comité Central, que un candidato externo a la coalición, especialmente una figura independiente, que representara a la "burguesía nacional”, podría servir para congregar un más amplio apoyo electoral sin ceder la hegemonía de la coalición a los partidos de centro. De hecho, llegaron a barajar la posibilidad de apoyar una candidatura del empresario centroizquierdista y ex ministro de Ibáñez, Guillermo del Pedregal ${ }^{19}$.

Sin embargo, el nombre de Allende fue imponiéndose al interior de los partidos Socialista y Comunista. En el Partido Socialista, la conducción de Salomón Corbalán, su nuevo Secretario General, se volvió de una importancia fundamental para la nominación de Allende. Dicho liderazgo representaba los cambios en las concepciones estratégicas que estaba viviendo el partido. Corbalán provenía del Partido Socialista Popular y, específicamente, del sector de Ampuero, por lo que en los últimos años había defendido líneas estratégicas antagónicas a las de Allende ${ }^{20}$. Sin embargo, en cuanto tenaz promotor de la línea del Frente de Trabajadores, Corbalán era un convencido de la necesidad de reforzar la alianza socialista-comunista y veía en Allende a un candidato cuyas credenciales podían

\footnotetext{
${ }^{18}$ Erich Schnake, Un socialista con historia. Memorias (Santiago: Aguilar, 2004) 131-132

${ }^{19}$ Entrevista a José Cademártori. Santiago. 11 de agosto de 2010. Archivo CIDOC-Universidad Finis Terrae. Véase también el "Informe de la Comisión Política al XXIV Pleno de Comité Cenrtral del Partido Comunista de Chile”. Principios 42 [Santiago] Mayo de 1957. Este punto también ha sido abordado por Torres 101-102. Con respecto a Guillermo del Pedregal, cabe destacar que también había desempeñado los cargos de Ministro de Hacienda y de Economía durante el gobierno de Juan Antonio Ríos y el de Vicepresidente Ejecutivo de CORFO bajo las administraciones de Pedro Aguirre Cerda y Carlos Ibáñez del Campo. Dicha trayectoria lo convertía en uno de los más destacados representantes del grupo de tecnócratas que en ese período dirigieron las agencias de planificación estatal y que desarrollaron importantes vínculos con el empresariado, especialmente industrial. Sobre dicho grupo véase Patricio Silva, En el nombre de la razón. Tecnócratas y política en Chile (Santiago: Universidad Diego Portales, 2010) 108-122

${ }^{20}$ El pensamiento de Corbalán y su visión sobre el programa del Partido Socialista está expresado de manera sistemática en Salomón Corbalán González, Partido Socialista (Santiago: La Academia de las Escuelas de Ciencias Políticas de las Universidades de Chile y de Concepción, 1957)
} 
reforzar esta opción ${ }^{21}$. La postulación de Allende fue ratificada por el Comité Central socialista. En un comienzo, Allende se rehusó obstinadamente a aceptar la candidatura. Sin embargo, "después de acaloradas discusiones" con Corbalán, "la directiva socialista le envío una carta conminatoria, exigiéndole que disciplinadamente aceptara”, a lo que Allende accedió $^{22}$.

En el Partido Comunista, la figura de Allende se impuso gracias a la popularidad que había alcanzado entre las organizaciones de base y entre los adherentes, en una oleada de entusiasmo que sorprendió a los cálculos más fríos y racionales de la dirección nacional. El dirigente José Cademártori recuerda que, pese a las reticencias iniciales, la dirigencia “percibía que en las bases y las poblaciones querían a Allende”, y que este era considerado como un "candidato representativo". Probablemente, en dicha actitud de las bases comunistas influía la firme oposición que Allende había mostrado a la Ley de Defensa Permanente de la Democracia y la persistencia con que había enarbolado un discurso que apuntaba a reforzar la Unidad Comunista-Socialista en la campaña presidencial de 1952 . El testimonio de Cademártori es reforzado por la prensa de la época, según la revista Vea, en donde se señaló que "en un caso curioso y único en la historia interna del Partido Comunista, se realizó una amplia discusión en cada una de las células de este partido, y estas, más los mandos comunales, regionales y la dirección nacional, acordaron propiciar la candidatura de Salvador Allende ante la convención presidencial" ${ }^{24}$. En todo caso, la dirección del Partido Comunista nunca terminó de cerrar sus opciones.

De este modo, la figura de Salvador Allende se transformó en la principal carta de comunistas y socialistas con miras a las elecciones de 1958. Los partidos recién mencionados esperaban refrendar dicha opción en una convención amplia, capaz de convocar a otros sectores políticos.

\section{La "Convención Presidencial del Pueblo"}

Los partidos del FRAP habían acordado dirimir la cuestión presidencial en una Convención que debía caracterizarse por su masividad y por la capacidad de representar a amplios grupos sociales organizados. Esta instancia, sería conocida como la "Convención Presidencial del Pueblo". En la convención no solo tendrían derecho a voto los representantes de los partidos que integraban el FRAP, sino también delegados de diversas organizaciones sociales, o "de masas" como fueron llamadas en dicho contexto. Entre estas

\footnotetext{
${ }^{21}$ Vea [Santiago] 18 de julio de 1957 y Jaime Suárez Bastías, Allende: visión de un militante (Santiago: Ochoymedio, 2008) 40

${ }^{22}$ Vea [Santiago] 18 de septiembre de 1957

${ }^{23}$ Entrevista a José Cademártori. Santiago. 11 de agosto de 2010. Archivo CIDOC-Universidad Finis Terrae.

${ }^{24}$ Vea [Santiago] 18 de septiembre de 1957. Este episodio también sirve para contradecir las visiones caricaturizadas sobre el funcionamiento interno del Partido Comunista, especialmente en cuanto a la total verticalidad que se le atribuye. Una interesante mirada sobre la cultura política del Partido Comunista puede encontrarse en el texto de Rolando Álvarez Vallejos, Arriba los pobres del mundo. Cultura e identidad política del Partido Comunista de Chile entre democracia y dictadura. 1965-1990 (Santiago: Lom, 2011).
} 
destacaban sociedades de socorros mutuos, sindicatos, comités de pobladores, clubes deportivos, centros culturales, organizaciones de "dueñas de casa” y medios de prensa adherentes a la izquierda. Fuera de estos sectores, la Convención permitió la participación por derecho propio de personeros de los "partidos populares" que hubieran desempeñado cargos públicos ${ }^{25}$.

Mediante este mecanismo, los dirigentes del FRAP, y en especial Salomón Corbalán, pretendían generar una instancia amplia, que facilitara la participación de las bases de los partidos políticos y de los independientes. Esta estrategia permitiría involucrar a organizaciones sociales en la campaña, las que facilitarían el trabajo territorial con posterioridad a la Convención ${ }^{26}$.

Estos afanes quedaron claros en las directrices que los Partidos del FRAP dieron a sus militantes, que apuntaban a reforzar las organizaciones sociales:

los organismos del FRAP que actúan en los sindicatos y organizaciones de pobladores, tendrán que organizarse inmediatamente en comités que impulsen la actividad de la Convención Nacional del Pueblo, haciendo un llamado a los grupos independientes para que se sumen y participen en la reunión nacional de septiembre, en la que el pueblo expresará su repudio a los candidatos de la reacción y el radicalismo, levantando un candidato que represente fielmente los intereses de la clase trabajadora ${ }^{27}$.

Para entender la necesidad de generar esta legitimidad extrapartidista al momento de elegir el candidato, debemos recordar que el sistema político chileno había vivido recientemente una crisis, marcada por un proceso de fragmentación y deslegitimación partidista, el que había llegado a su cúspide en las elecciones parlamentarias de 1953. En dicho momento, a la división de la mayoría de los partidos históricos como consecuencia de la discusión de la Ley de Defensa Permanente de la Democracia, se sumó la irrupción de pequeños movimientos, principal aunque no exclusivamente, nacionalistas e ibañistas ${ }^{28}$. Tras las elecciones parlamentarias de 1957 el ibañismo estaba en declinación y los partidos históricos habían vivido un proceso de recuperación. Sin embargo, la decadencia del ibañismo produjo una diáspora de pequeñas organizaciones nacional-populares, la mayoría de las cuales obedecían a liderazgos caudillistas ${ }^{29}$. La inestabilidad de la situación partidista podía abrir el campo para el surgimiento de liderazgos personalistas y divisiones. En este marco, las directivas de los partidos del FRAP querían "evitar los riesgos de tentaciones y fraccionalismos en torno a la elección presidencial" ${ }^{30}$. Por ello querían generar un acto masivo, cuya legitimidad fuera más allá del ámbito partidista.

\footnotetext{
${ }^{25}$ Véase el "Reglamento de la convención". Boletín del Comité Central del PS 1 [Santiagol julio-agosto de 1957: 8

${ }^{26}$ Vea [Santiago] 18 de julio y 11 de septiembre de 1957.

${ }^{27}$ "Convención Presidencial del Pueblo". Boletín del Comité Central del PS 1 [Santiagol julio-agosto de 1957: 8

${ }^{28}$ Jaime Antonio Etchepare Jensen, “Ibáñez y su revolución de 1952”, Política 26 (1991), 61-95.

${ }^{20}$ Tomás Moulian, El gobierno de Ibáñez: 1952-1958 (Santiago: FLACSO, 1986) 55

${ }^{30}$ Suárez 40
} 
En todo caso, la apertura a las organizaciones sociales se hizo bajo la firme organización del FRAP, y de hecho, en algunos casos, la presencia de estas se exageró artificialmente para generar una sensación de movilización de masas. Ricardo Núñez, en ese entonces un joven socialista, recuerda que tuvo "la oportunidad de Participar en la Convención por la Juventud Socialista, pues yo era dirigente del Liceo Valentín Letelier. En todo caso, fui acreditado, hasta hoy no sé por que, como representante del Sindicato del Cuero y el Calzado" ". Este testimonio es coherente con las informaciones aportadas por Osvaldo Puccio, secretario personal de Allende, quien en sus memorias sostuvo que "cada partido tenía una cuota de representantes, que no iban a llegar como representantes de partidos sino de organizaciones de masas" ${ }^{\text {32 }}$.

Como habíamos sostenido, a la convención no sólo se presentaron los partidos del FRAP, sino que también concurrieron otras agrupaciones reformistas de centroizquierda. Por una parte, se presentó la Alianza Nacional de Trabajadores, dirigida por Mamerto Figueroa Parot, ex alcalde-intendente de Santiago en la reciente administración de Ibáñez. Se trataba de una organización nacionalista de centroizquierda, la que incluso congregó a católicos reformistas, intentando reorganizar parte de las agrupaciones que se estaban desperdigando debido a la decadencia del ibañismo. Por otra parte, también se hizo presente el Partido Radical Doctrinario, de Rudecindo Ortega. Esta facción del radicalismo, se había escindido de su partido de origen debido a que se había negado a aprobar la Ley de Defensa Permanente de la Democracia y luego, en 1952, había apoyado la candidatura de Carlos Ibañez $z^{33}$.

Junto con Salvador Allende, otros candidatos se presentaron a la convención. En primer lugar, se encontraba Guillermo del Pedregal, quien lanzaba una candidatura como independiente, defendiendo sus credenciales de representante del empresariado nacional progresista y de haber sido uno de los impulsores de la Corporación de Fomento de la Producción (CORFO) y ex ministro de Ibáñez. En segundo lugar, estaba Francisco Cuevas Mackenna, ex presidente de la Sociedad Nacional de Minería, quien si bien no poseía una trayectoria política vinculada a la izquierda, veía en esta convención la oportunidad de levantar una candidatura. En tercer lugar, se presentó Humberto Mewes Bruna, ex contralor, quien abandonó su puesto al acercarse a la izquierda y distanciarse de las políticas anticomunistas implementadas por Gabriel González Videla. La candidatura de Mewes fue levantada por el Partido del Trabajo. En cuarto lugar, participó Alejandro Serani, representante del Partido Democrático, que hasta ese momento se había desempeñado

\footnotetext{
${ }^{31}$ Joaquín Fernández Abara, Álvaro Góngora Escobedo y Patricia Arancibia Clavel, Ricardo Núñez. Trayectoria de un socialista de nuestros tiempos (Santiago: Universidad Finis Terrae, 2013) 32.

${ }^{32}$ Osvaldo Puccio, Un cuarto de Siglo con Allende. Recuerdos de su secretario privado (Santiago,: Emisión, 1985) 46

${ }^{33}$ Sobre estas colectividades véase Puccio 45 y Jaime Etchepare Jensen, "El advenimiento de Gabriel González Videla al Gobierno y el Fracaso de la Unión Nacional (1946-1948”), Revista de Historia 2 (1992) 100
} 
como Gran Maestro de la Gran Logia de Chile. Finalmente, en sexto lugar, entró a la competencia Rudecindo Ortega, por el Partido Radical Doctrinario ${ }^{34}$.

La Convención tuvo lugar entre los días 15 y 17 de septiembre de 1957, en los salones del Congreso Nacional. Se trató de una manifestación de una masividad inédita, a la cual asistieron tres mil ciento veinte y siete convencionales de distintas partes del país, de los cuales mil seiscientos tenían derecho a voto. La estética que rodeó a la "Convención Nacional del Pueblo" era el fiel correlato de los afanes nacionalistas y antiimperialistas del FRAP. Según Ricardo Núñez:

Fue un acto hermoso, al que vino gente de todo Chile. Tengo un bonito recuerdo, porque en la entrada del Congreso habían huasos que bailaban cueca; llegó gente de la Isla de Pascua que bailaron el sau-sau, también se hicieron presentes los mapuches. Incluso asistieron mineros y campesinos con sus trajes de trabajo. Fue una instancia muy folclórica, que dejó en evidencia la imaginación popular ${ }^{35}$.

La convención no sólo serviría para elegir al abanderado presidencial, sino también para que los delegados discutieran y ratificaran la plataforma programática. Con esto, se esperaba involucrar a las organizaciones de base y a los partidos pequeños en la campaña. Para estos efectos, se organizaron diversas comisiones que debían discutir los distintos puntos del programa.

La elección del abanderado de la izquierda se haría mediante seis rondas de votación, en cada una de las cuales se iría eliminando a uno de los candidatos hasta que quedara el vencedor. A través de este mecanismo, los partidos más grandes, y en especial el Socialista, pretendían que los candidatos independientes y de agrupaciones menores tuvieran oportunidad de ganar algunas de las etapas de la convención y hacer una demostración de fuerza, lo que generaría de su parte un mayor compromiso con la campaña y legitimaría la decisión de la Convención. Esto requería una acción coordinada y disciplinada por parte de las bases militantes, que en muchos casos deberían votar en primera instancia por candidatos que no eran de su simpatía para fortalecer esta estrategia unitaria. Sin embargo, la estrategia se mostró inútil, ya que diversos sectores, principalmente independientes de centro izquierda y socialistas, se volcaron inmediatamente de manera masiva hacia Allende. Según Osvaldo Puccio, "en la primera votación Allende ganó con 530 votos contra 400 del siguiente. Con esto arrasó la Convención. Se acabó. Todo nuestro esquema se rompió” "

Efectivamente, la estrategia original de los partidos del FRAP, que pretendía transformar a la Convención en una instancia de protagonismo para agrupaciones menores y candidatos independientes, se había desarmado. Y si bien dicha situación causó júbilo entre las bases militantes e independientes que habían votado por Allende, generó una gran

\footnotetext{
${ }^{3 *}$ Véase Ercilla [Santiago] 18 de septiembre de 1957. También véase Arancibia 288-289. En este último texto se omite la participación de Serani y se sostiene que Mamerto Figueroa se habría presentado como candidato a la Convención.

${ }^{35}$ Fernández Abara et al 32

${ }^{36}$ Puccio 48
} 
preocupación entre los dirigentes del FRAP, quienes temían que pudiera producirse un quiebre. El propio Allende, inquieto ante una posible ruptura de la unidad de las agrupaciones de izquierda, llegó a ofrecer su renuncia. Sin embargo, la dirigencia socialista y comunista, e incluso el propio Guillermo del Pedregal sostuvieron que se había hecho evidente la voluntad de la Convención, en torno al nombramiento de Allende y que no tenía sentido continuar con los procedimientos preestablecidos. Finalmente, tras largas reuniones entre los partidos y los precandidatos, y después de vencer la resistencia de grupos minoritarios de los partidos socialista y democrático, quienes querían lanzar un candidato independiente para conquistar los votos centristas, Allende fue proclamado "por unanimidad y ovación” ${ }^{37}$.

Una vez proclamado en medio de una fervorosa ovación, y tras ser presentado por el periodista Juan Emilio Pacull, Allende pronunció un discurso de una hora y media, en que llamaba a reforzar la unidad socialista-comunista y destacaba algunos de los puntos principales de su programa:

La unidad socialista-comunista debe ser la piedra angular de este movimiento que se ha puesto en marcha. Y esta unidad tenemos que irla extendiendo a cada vez más amplios sectores sin sectarismos.

Tengo la certeza de que superaremos esta histórica jornada de 1938 con el Frente Popular. Porque ahora somos eso y mucho más. Somos la avanzada del progreso de Chile. Somos la conciencia viva de la nación que se ha puesto en marcha. Estamos aquí para reafirmar nuestra insobornable voluntad de lucha.

Y que nadie piense que este es un saludo a la bandera. Saludaremos a la bandera de la patria con emoción cuando entremos a la Moneda, después de triunfar en la elección. Y la seguiremos realizando en cada una de las realizaciones que hagamos, con cada una de las conquistas que logremos a favor del progreso, de la cultura, del bienestar de nuestro pueblo, de su independencia económica, de la soberanía nacional $^{38}$.

En su discurso Allende realizó un intento de articular las distintas sensibilidades políticas que convivían al interior del FRAP. Así, al mismo tiempo que resaltó la alianza comunista-socialista como núcleo fundamental de su candidatura, insistió en la necesidad de buscar apoyos sociales y políticos más amplios. Del mismo modo enunció varios de los lineamientos que tendría el programa de su candidatura.

\section{El Programa}

El programa que fue aprobado y recibió algunas modificaciones durante la Convención, era una versión más precisa y elaborada de los lineamientos programáticos del FRAP del año 1956. Las principales medidas del programa fueron sistematizadas y

\footnotetext{
${ }^{37}$ Vea [Santiagol 18 de septiembre de 1957

${ }^{38}$ Vea [Santiago] 18 de septiembre de 1957
} 
Joaquín Fernández, Allende, el allendismo y los partidos: El Frente de Acción Popular ante las elecciones presidenciales de 1958 / Allende, the Allendism and the political parties: The Popular Action Front and the 1958's presidential elections, Revista Izquierdas, № 23, abril 2015, ISSN 0718-5049, IDEA-USACH, pp. 157190

condensadas en 1958 por una "Convención de técnicos y profesionales" y quedaron plasmadas en el texto Medidas concretas del Gobierno Popular desarrollado con anterioridad por un grupo de profesionales de los partidos del FRAP con la colaboración de figuras independientes ${ }^{39}$. Entre los autores de la plataforma económica, destacaban Jaime Barrios, José Cademártori, Gonzalo Martner, Orlando Millas, Max Nolff y Pedro Vuskovic $^{40}$. En su elaboración confluyeron una mezcla de los conocimientos experienciales que habían adquirido los economistas chilenos a la luz de su vivencia del "modelo CORFO"; las ideas de la "economía del desarrollo", especialmente las que estaban mediadas por el pensamiento estructuralista de la CEPAL y algunos elementos de la política económica del

\footnotetext{
${ }^{39}$ V.V.A.A. Medidas concretas del Gobierno Popular (Santiago: Imprenta Lautaro, 1958). También véase la "Plataforma programática de la candidatura presidencial del pueblo". Boletín del Comité Central del PS 2 [Santiago] septiembre-octubre de 1957 4-6. Una síntesis más apretada del programa, pero que refleja cómo estas medidas fueron presentadas al grueso de la población, puede encontrarse en Ahora si [Santiago] 2 de junio de 1958. Una interesante síntesis del programa de Allende puede encontrarse en Torres 111-115

${ }^{40}$ Con respecto a los autores de la plataforma económica, cabe detenerse en sus trayectorias profesionales intelectuales y militantes. Jaime Barrios (1925-1973) era Ingeniero Comercial de la Universidad de Chile. Militante del Partido Comunista del que se alejaría poco tiempo después, tras su paso por la Cuba revolucionaria, para acercarse al Partido Socialista. Miembro del Consejo de Redacción de Punto Final, durante el gobierno de la Unidad Popular fue Gerente General del Banco Central. José Cademártori (1930) era Ingeniero Comercial de la Universidad de Chile y militante del Partido Comunista. A inicios del segundo gobierno de Ibáñez se había desempeñado como asesor en los ministerios de Hacienda y Minería. En 1957 fue electo diputado por la Séptima Agrupación Departamental de Santiago, por donde fue reelecto consecutivamente en 1961, 1965 y 1969. Durante el gobierno de la Unidad Popular fue Ministro de Economía. Gonzalo Martner (1928 -2002) era Abogado e Ingeniero Comercial de la Universidad de Chile, con estudios de postgrado en Washington. Independiente cercano al Partido Socialista, por varios años se desempeñó como economista del Ministerio de Hacienda y de la CEPAL. Durante el gobierno de la Unidad Popular fue Ministro Director de ODEPLAN. Orlando Millas (1918-1991) estudió en la Escuela de derecho de la Universidad de Chile. Se desempeñó como periodista, llegando a ser director del diario El Siglo. Militante del Partido Comunista, aunque en su juventud fue parte de la Juventud Socialista, participó en la Conferencia Económica Internacional celebrada en Moscú el año 1952. En 1961 fue electo diputado por la Séptima Agrupación Departamental de Santiago, por donde fue reelecto en 1965 y 1969. Fue ministro de Hacienda y de Economía durante el Gobierno de la Unidad Popular. Max Nolff (1919) era Ingeniero de la Universidad de Chile y se desempeñó Economista. Independiente de izquierda cercano a Allende, fue economista de la CEPAL y uno de los fundadores de la revista Panorama Económico. Durante el Gobierno de la Unidad Popular fue Vicepresidente de CODELCO. Pedro Vuskovic (1924-1993) fue Ingeniero Comercial de la Universidad de Chile. Era independiente de izquierda, aunque cercano al Partido Socialista, al que entraría a militar durante el gobierno de la Unidad Popular. Profesor de Economía de la Universidad de Chile, fue economista de la CEPAL y miembro del Círculo de Economistas. Durante el gobierno de la Unidad Popular fue Ministro de Economía. Como podemos observar, si bien varios de ellos eran militantes, había una presencia relevante de independientes de izquierda. Su participación en la discusión del programa se encontraba legitimada por su experticia en el área económica. En este sentido, la gran mayoría de ellos eran ingenieros comerciales formados en la Universidad de Chile. En general tuvieron experiencia trabajando en el Estado y en organismos internacionales, viéndose fuertemente influenciados por el desarrollismo cepalino. Véase Empresa Periodística de Chile, Diccionario biográfico de Chile. Duodécima edición. 1962-1964 (Santiago: Empresa Periodística de de Chile, 1964) y Armando de Ramón, Biografías de chilenos: miembros de los poderes Ejecutivo, Legislativo y Judicial (1876-1973) (Santiago: Ediciones Universidad Católica de Chile, 2003).
} 
bloque socialista, con énfasis en los aspectos referidos a planificación estatal y transición hacia una estructura productiva industrial ${ }^{41}$.

El Programa de la candidatura del FRAP se dividía en cinco grandes puntos. Estos eran: 1) más democracia, 2) más desarrollo económico, 3) más bienestar social, 4) más independencia nacional y, finalmente, 5) cumpliremos el programa.

Con respecto a las medidas políticas, estas apuntaban a restaurar las libertades públicas y sindicales y a profundizar el proceso de democratización. La democratización era entendida no sólo en términos políticos, sino también como expansión de los derechos sociales y económicos. Para lograr estos objetivos, llamaban a promulgar una reforma electoral, a disminuir las atribuciones del Presidente de la República, a descentralizar la administración y el poder político mediante la creación de asambleas provinciales y a crear una Asamblea Constituyente.

En el ámbito económico, el programa dejaba en evidencia lineamientos desarrollistas e industrializadores, junto con tendencias antimonopólicas, anti-latifundistas y antiimperialistas. Además, planteaba la necesidad de generar una mejor redistribución de las rentas. Para lograr estos objetivos, proponía fomentar la industrialización, mejorando el abastecimiento de bienes de consumo para el mercado interno. Con este fin, el Estado debería intensificar los programas de extracción y producción de recursos energéticos y estimular el ahorro y las empresas productivas. Si bien no cuestionaba la propiedad privada industrial, llamaba a controlar a las empresas monopólicas y a "aprovechar los recursos de la Gran Minería” mediante una política de nacionalizaciones. El problema de la tenencia de la tierra fue expuesto desde una lógica económica y desarrollista. Se destacó la necesidad de "terminar con las tierras improductivas", mediante la expropiación. La tierras expropiadas, se planteó entonces, serían subdivididas en propiedades medianas, en las que se crearían cooperativas de producción, que las entregarían "directamente a los campesinos, según sean las condiciones de cada zona”. Finalmente, el programa resaltaba la importancia de hacer una reforma tributaria, que instaurara un "impuesto progresivo a la renta".

En el ámbito social, el programa centró sus preocupaciones en solucionar el problema de la vivienda, transformándose en uno de los tópicos más recurrentes de su campaña. Para ello, llamaba a impulsar la autoconstrucción con "créditos" y "ayuda técnica" del Estado. En este sentido, la campaña fomentaba los procesos de autogestión de los pobladores e incorporaba sus tradiciones organizativas al plan de gobierno ${ }^{42}$. También recibieron una importante atención los problemas derivados de la desnutrición, el

\footnotetext{
${ }^{41}$ Entrevista a José Cademártori. 11 de agosto de 2010. Archivo CIDOC-Universidad Finis Terrae. Al respecto, es necesario tener en cuenta que hasta la implementación de la Alianza para el Progreso, en la década de 1960, el programa de desarrollismo estructuralista de la CEPAL había generado resistencias en las altas esferas del gobierno estadounidense. Si bien la CEPAL mantuvo su carácter de organismo técnico independiente y sus planteamientos desarrollistas no eran socialistas, varios de sus economistas más destacados derivaron a posturas de izquierda, entre ellos el mexicano Juan Noyola, quien terminó transformado en asesor del gobierno de Fidel Castro en Cuba a comienzos de la década de 1960. Véase Carlos Bazdresch, "El Pensamiento de Juan F. Noyola”, El trimestre económico 198. 50. 2 (junio de 1983) 567-593

${ }^{42}$ Alexis Cortés, "El movimiento de pobladores chilenos y la población La Victoria: ejemplaridad, movimientos sociales y derecho a la ciudad”, EURE 40. 119 (enero de 2014) 239-260
} 
analfabetismo y la previsión. Con este fin, resaltaba la necesidad de mejorar la cobertura y la calidad de los organismos estatales encargados de la "seguridad social", fomentando la participación de los trabajadores en su dirección.

En el plano internacional, la plataforma presidencial planteaba la necesidad de derogar los convenios militares vigentes con Estados Unidos, al mismo tiempo que instaba a que Chile adoptara una política exterior autodefinida como "pacifista", solidarizando con la causa de los países "coloniales y dependientes". El programa sostenía que era imprescindible establecer relaciones diplomáticas y comerciales con todos los países del mundo.

Finalmente, el último punto establecía las condiciones que harían posible la realización de este programa, sosteniendo que la capacidad económica del país, en los ámbitos industrial, minero y agrícola se encontraba subutilizada, lo que facilitaría la implementación de estas medidas.

En más de una ocasión se ha sostenido que el programa de 1958 habría sido la plataforma más radical que ha presentado la izquierda chilena entre las décadas de 1950 y $1970^{43}$. Dicho juicio podría tener asidero al hacer una lectura directa de las medidas de cada programa. Sin embargo, estas providencias deben ser entendidas en su contexto y, además, se debe tener en cuenta la manera en que fueron publicitadas. El programa de 1958 fue expuesto como una plataforma de reformas profundas, en el que los sectores medios tendrían asignado un papel histórico relevante. Además, en un contexto previo a la revolución cubana, el programa no se tiñó de una retórica admirativa hacia procesos políticos de corte insurreccional. De hecho, y al igual que en 1952, la candidatura insistió en la similitud que presentaban sus orientaciones programáticas y las medidas de la CEPAL ${ }^{4}$. Quizás una de las razones que expliquen esta impresión generalizada en torno al programa de 1958 sea el alto nivel de especificidad con que fueron mostradas las medidas en el.

\section{La Campaña}

Allende con su claro lenguaje pedagógico, expresó los lineamientos generales del programa en un discurso realzado en la Plaza Bulnes el 2 de junio de 1958:

Producir es una de las metas que informa nuestro programa de acción. Pero planteamos la tarea de nuestro desenvolvimiento económico atendiendo a nuestra condición de país subdesarrollado, aplicando las fórmulas renovadas de la economía moderna y utilizando las funciones que corresponden al Estado en un sentido moderno. No podemos cimentar nuestro desarrollo con el sistema europeo y norteamericano del siglo XIX, basado en brutal explotación, para obtener la capitalización a que aspiramos (...) El gobierno popular hará que la política financiera y económica del gobierno esté orientada a servir las necesidades del pueblo, de progreso colectivo de la nación . No hará y no permitirá que los

\footnotetext{
${ }^{43}$ Puccio 44

${ }^{4}$ Ahora si [Santiago] 7 de julio de 1958
} 
grandes monopolios, como sucede hasta hoy día, le dicten a nuestro gobierno lo que debe y lo que no debe hacer en asuntos económicos y financieros. El gobierno popular hará que las leyes tributarias y las que amparan el trabajo de las clases asalariadas se mejoren íntegramente. Hará que los ricos den más de su riqueza y los pobres menos de su pobreza ${ }^{45}$.

El énfasis que la campaña puso en las políticas de bienestar social y, especialmente, en el mejoramiento de los problemas de la vivienda, se inscribe en una larga tradición en la izquierda chilena. Sin embargo, la especial urgencia que adquirió en la campaña de Allende de 1958 se explica por la emergencia de algunos procesos sociales de suma importancia que estaba viviendo el país. Estos eran la aceleración sin precedentes de la migración campociudad y el crecimiento de zonas de pobreza en las afueras de los centros urbanos, caracterizadas por la falta de vivienda. Hacia fines de la década de 1950, estos problemas fueron tematizados debido a que se manifestaron en acontecimientos llamativos. El descontento de amplios sectores sociales ya se había hecho notar en las protestas de inicios de abril de $1957^{46}$. Sin embargo, el hito más significativo acaeció en octubre de 1957, al poco tiempo de finalizada la Convención del Pueblo cuando tuvo lugar la Toma de la Victoria, realizada por los habitantes de las "poblaciones callampas” aledañas al Zanjón de la Aguada. Se trataba de uno de los primeros actos de fuerza, de gran connotación pública, realizado por el movimiento de pobladores. Los partidos del FRAP, y en especial el Partido Comunista, jugaron un rol importante en la organización y apoyo de la toma, y el propio Salvador Allende, pese a los consejos de sus asesores y de las directivas de los partidos, dio su apoyo personal a estas manifestaciones ${ }^{47}$.

La elección de 1958 no solo reflejó estos conflictos sociales emergentes, sino que también fue una clara manifestación de los cambios que estaba viviendo el sistema de partidos chileno. Derecha, centro e izquierda llevaron sus propias candidaturas, dejando en evidencia la recuperación de la política partidista institucionalizada, pero, al mismo tiempo el agotamiento y rigidización del juego de alianzas. La derecha, formada por Liberales y Conservadores, presentó la candidatura del ingeniero y empresario Jorge Alessandri Rodríguez; los radicales, animados por la recuperación electoral que habían vivido en las elecciones parlamentarias de 1957, decidieron presentar a Luis Bossay Leiva; y un recién formado Partido Demócrata Cristiano enarboló la candidatura de Eduardo Frei Montalva. La política chilena comenzaba a dividirse en tres tercios, al mismo tiempo que el centro, posición donde hasta entonces los radicales gozaban de un rol hegemónico, pasó a ser disputado por los democratacristianos ${ }^{48}$.

\footnotetext{
${ }^{45}$ Salvador Allende, "El Progreso debe surgir del pueblo”, Clarín [Santiago] 3 de junio de 1958

${ }^{46}$ Sobre estros eventos véase Pedro Milos, Historia y memoria. 2 de abril de 1957 (Santiago: Lom-Universidad Alberto Hurtado-2007)

${ }^{47}$ Véase Arrate y Rojas 323-324, también Mario Garcés, Tomando su sitio. El movimiento de pobladores en Santiago, 1957-1970 (Santiago: LOM, 2002) 121-150

${ }^{48}$ Arancibia 296-297 y Torres 79-136
} 
A estos candidatos se sumó un quinto postulante. Un outsider con un pequeño arrastre electoral, pero que en el contexto de fragmentación política y alta competitividad existente podía llegar a tener un rol importante. Se trataba de Antonio Zamorano Herrera. Zamorano, quien pasó a ser conocido como "El Cura de Catapilco" era un sacerdote retirado, quien había ejercido su ministerio sacerdotal en la localidad rural de Catapilco, al norte de Valparaíso. Enarbolando una retórica nacional popular simplista, cargada de reminiscencias folclóricas y religiosas, Zamorano había logrado ser electo regidor por Zapallar y luego diputado por Valparaíso y Quillota. En su labor en el Congreso, se había mostrado cercano al grupo parlamentario del FRAP. Sin embargo, se animó a lanzar su candidatura independiente. Siempre existieron sospechas de que esta fue financiada por la derecha para dividir al electorado de izquierda y debilitar la candidatura de Allende, sin embargo estas nunca pudieron ser corroboradas". En todo caso, el "Cura de Catapilco" movilizó una pequeña fracción del electorado popular con un discurso moralista. Probablemente, dicho modo de interpelar a la ciudadanía influyó en sectores del electorado que anteriormente se habían mostrado proclives al ibañismo, compitiendo con el discurso de crítica antioligárquica enarbolado por la candidatura de Allende.

En este marco de división de las fuerzas políticas, pronto se advirtió el gran potencial de triunfo de la derecha. El 23 de abril de 1958 se realizó una elección complementaria para diputado en el Tercer Distrito de Santiago. El Tercer Distrito era una gran circunscripción electoral en Santiago, que englobaba a comunas de una composición social muy diversa, por lo que estos comicios extraordinarios habían sido asumidos por gran parte de la opinión pública como una suerte de vaticinio de lo que sucedería en la elección presidencial. Los comicios dieron una amplia victoria a Enrique Edwards, candidato de liberales y conservadores, por sobre el resto de los postulantes ${ }^{50}$.

La elección complementaria fue asumida como una advertencia por las fuerzas políticas de centro e izquierda. El 27 de marzo de 1958 los partidos del FRAP, la Democracia Cristiana, el Partido Radical, el Partido Nacional y el Partido Agrario Laborista, formaron el Bloque de Saneamiento Democrático. El Bloque planteaba como objetivo la derogación de la Ley de Defensa de la Democracia, restituyendo el pluralismo político y reincorporando a la ciudadanía activa a los afectados que habían sido borrados de los registros electorales ${ }^{51}$. Al mismo tiempo se planteó la necesidad de modificar los mecanismos de inscripción electoral, facilitándolos y volviéndolos permanentes, y combatir el cohecho, mediante la instauración de la cédula única de votación ${ }^{52}$. Como vemos, este pacto parlamentario se movilizaba por objetivos de largo alcance, como eran la restauración del pluralismo político, el incremento en la participación electoral y la instauración de mecanismos electorales transparentes. Sin

\footnotetext{
${ }^{49}$ Arancibia 296-297

${ }^{50}$ Clarín [Santiago] 24 de abril de 1958

${ }^{51}$ Sobre el tema véase Alonso Daire, Derogación de la Ley de Defensa de la Democracia. Legalilidad al comunismo en Chile, 1958. Tesis para optar al grado de Licenciado en Historia (Santiago: Pontificia Universidad Católica de Chile, 1989)

${ }^{52}$ Carlos Huneeus, La Guerra Fría Chilena. Gabriel González Videla y la Ley Maldita (Santiago: Debate, 2008) 336.
} 
embargo, al mismo tiempo, tenía una utilidad más práctica e inmediata para el conjunto de agrupaciones de centro e izquierda que lo componía, y esta era la neutralización de la derecha con miras a la elección de 1958, mediante la demolición de las prácticas clientelísticas tradicionales que hasta el momento le habían asegurado un importante nivel de apoyo electoral. En efecto, la combinación de partidos que impulsó estas medidas fue conocida como Pacto Parlamentario A-B-F (Allende, Bossay y Frei, respectivamente candidatos del FRAP, el Partido Radical y la Democracia Cristiana) y también como TOCOA (Todos Contra Alessandri) $^{53}$. La acción del Bloque de Saneamiento Democrático contó con el apoyo del gobierno, y permitió que se aprobara con suma rapidez una reforma electoral, el 17 de mayo de 1958, pudiendo así estar vigente para las elecciones de dicho año. Las reformas implicaban la instauración de una cédula única de votación, la prohibición de los pactos provinciales, el castigo con penas de cárcel a los implicados en el delito de cohecho y la reincorporación a los registros electorales de los ciudadanos borrados durante la vigencia de la Ley de Defensa Permanente de la Democracia. Las negociaciones sobre la Derogación de la Ley de Defensa de la Democracia resultaron aún más largas. El objetivo se logró el 2 de agosto de 1958. Sin embargo, y debido a las condiciones impuestas por el gobierno, a cambio de la derogación de la "ley maldita" debió aprobarse una nueva Ley de Seguridad Interior del Estado, que mantuvo algunas limitaciones a la acción de los sindicatos ${ }^{54}$.

La creación de este pacto generó expectativas diversas en las dirigencias de los partidos de centro e izquierda. Las colectividades se vieron ante la disyuntiva de enfocarlo como un pacto de corto plazo, orientado a la generación de reformas institucionales, o como la posibilidad de sentar las bases de una candidatura única de centro-izquierda. Diversas personalidades y facciones en los partidos comenzaron a pronunciarse con el fin de generar una coalición más permanente de centroizquierda. En la izquierda surgieron voces en el propio Partido Comunista que llamaron a unir a los radicales con la izquierda en la candidatura de Allende. Sin embargo, con suma prontitud, el Comité Ejecutivo de la candidatura, y el propio Salvador Allende, dejaron en claro que solo aceptaban el acuerdo en el "campo parlamentario" y para los fines específicos ya mencionados ${ }^{55}$. Esto no fue óbice para que la candidatura de Allende buscara el apoyo de fracciones desprendidas de partidos centristas y de algunos grupos derivados del ibañismo. Con respecto al primer caso, Allende recibió en plena campaña el apoyo de la Intransigencia Radical Antiimperialista, o IRA, un grupo de izquierda desprendido del Partido Radical. Del mismo modo, buscó contar con el apoyo del precandidato Abdón Parra, militar en retiro y ex ministro de Ibáñez, quien había logrado acaudillar a varias agrupaciones de cristianos evangélicos y de suboficiales en retiro. Sin embargo, las tentativas de conversación con Parra se vieron abortadas, y este, finalmente, se unió a la campaña de Eduardo Frei ${ }^{56}$.

\footnotetext{
${ }^{53}$ Ercilla [Santiago] 9 de abril de 1958.

${ }^{54}$ Huneeus 342-353 y Moulian 42-47

${ }^{55}$ Clarín [Santiago] 27 de marzo y 11 de abril de 1958.

${ }^{56} \mathrm{Al}$ respecto véase Puccio 76-77, Arturo Olavarría Bravo, Chile entre dos Alessandri. Memorias Políticas. Tomo II (Santiago: Nascimento, 1962) 373-374 y "Parra traicionó a evangélicos", Ahora Si [Santiago] 20 de junio de 1958.
} 
Fieles al esquema de llevar al poder a una coalición en la que los "partidos de los trabajadores" tuvieran la hegemonía, el lema de la campaña fue "ahora le toca al pueblo"

Poco a poco comenzó a quedar en evidencia que la gran disputa de la elección enfrentaría a Allende con Alessandri. La organización de la propaganda por parte de la candidatura de izquierda se volvió más compleja que en las campañas anteriores. Esto debido a que debían enfrentar un desafío novedoso: la candidatura de Jorge Alessandri estaba haciendo uso de modernas estrategias de marketing político. La empresa Storand S.A. se hizo cargo de orientar la campaña del candidato derechista, profesionalizando una actividad que hasta entonces se había realizado de manera artesanal y algo improvisada ${ }^{58}$. La campaña allendista tomó diversas medidas para enfrentar estas dificultades. En un comienzo se comisionó al periodista Walter Duhalde para que preparara boletines informativos, y confeccionara un "diario mural”. Este quedó plasmado en el periódico Ahora Si, una hoja informativa, de una plana, que podía ser repartida o pegada en las paredes. Esta contenía información de la campaña, avisos para las organizaciones territoriales, exposiciones de puntos programáticos e interpelaciones a las candidaturas contrarias. Con posterioridad, el comando decidió contratar a un grupo de reporteros simpatizantes de izquierda para que realizaran mejor los trabajos de divulgación de actividades, constituyendo un comando de prensa $^{59}$. La campaña también recibió el decidido apoyo de los diarios El Siglo, del Partido Comunista, del Vespertino Noticias de Última Hora, vinculado al Partido Socialista, del diario Clarín y el vespertino La Gaceta, a cargo del empresario periodístico Darío Sainte Marie, conocido como Volpone, un heredero del populismo ibañista. Los diarios de Volpone difundieron con lujo de detalles la acción del candidato del FRAP, y con un lenguaje irónico y cercano a los usos populares reforzaron la tónica anti oligárquica de la campaña. No adjetivar.

La propaganda de la campaña allendista no polemizó mayormente con las candidaturas de Frei, Bossay y Zamorano, enfocando sus ataques en la de Alessandri. Dicha constatación se condice con algunos de los recuerdos de los involucrados:

nuestro adversario era don Jorge Alessandri y la derecha. La campaña de la izquierda y del FRAP se dirigió especialmente en su contra. Yo me a cuerdo de los eslóganes contra Alessandri pero no me acuerdo de los eslóganes contra Eduardo Frei, el candidato democratacristiano, ni contra Luis Bossay, el candidato radical. Recuerdo también las peleas que teníamos durante la campaña; no eran violentas, pero eran peleas al fin y al cabo. Las hicimos grupos de estudiantes del pedagógico, básicamente en las zonas que hoy corresponden a Nuñoa y Providencia, en todo ese sector. Salíamos en la noche y nos encontrábamos con brigadas de Alessandri,

\footnotetext{
${ }^{57}$ Suárez 45

${ }^{58}$ Este tema ha sido tratado en profundidad en la tesis de Catalina Antúnez, A usted lo necesito! La campaña presidencial de Jorge Alessandri Rodríguez en 1958. Tesis para optar al grado de Licenciada en Historia (Santiago: Universidad Alberto Hurtado, 2009). En el texto, la autora estudia la introducción de estrategias profesionalizadas de marketing político y realiza análisis iconológicos e iconográficos de la propaganda visual del candidato de la derecha.

${ }^{59}$ Ercilla [Santiago] 14 de mayo de 1958
} 
no de Frei ni de Bossay. Las peleas tenían lugar en la calle, dirimiendo quien tenía la posibilidad de poner un cartel $^{60}$.

En todo caso, los vínculos con los partidos de centro, y especialmente con el radicalismo generaron pugnas entres los dos principales partidos del FRAP, especialmente a inicios de la campaña. Mientras que el Partido Comunista, a través de sus dirigentes, hizo declaraciones buscando el apoyo del radicalismo para la candidatura del FRAP, los socialistas rechazaron con vehemencia dichos acercamientos ${ }^{61}$. Al respecto, el Comité Central del Partido Socialista hizo saber, de manera oficial, su oposición a tales acercamientos:

Desde el punto de vista de fondo, el llamado comunista era y es, a juicio de nuestro Partido, profundamente inconveniente, peligroso y perjudicial para la candidatura de Allende. En efecto, el llamado envuelve una oferta al Partido Radical, en su conjunto, representado por su actual directiva, para entrar en tratos con nosotros, quedando tácitamente entendido que para lograrlo la candidatura de Allende debe entrar en compromisos con ese partido.

Es evidente que tales compromisos debilitarían la confianza popular en la candidatura, darían personería de izquierda ala directiva reaccionaria radical, permitiéndole por su intermedio introducir el contrabando reaccionario en el interior de nuestras fuerzas. Por otro lado el compromiso con el radicalismo en su conjunto significa un acuerdo con la red de intereses reaccionarios vinculados al radicalismo y esferas dirigentes, que de este modo se verían incorporados a un movimiento político que, precisamente, debe tener como objetivo combatir tales intereses $^{62}$.

La campaña de Allende cuestionó los afanes de Jorge Alessandri de mostrarse como candidato independiente y, sobre todo, su vinculación a los grandes grupos del empresariado monopólico. A estas críticas se sumaron ataques personales, que buscaban generar hilaridad con bromas sobre la supuesta homosexualidad del abanderado derechista ${ }^{63}$. Sin embargo, el uso de estas generó la indignación del propio Salvador Allende, quien reprendió a Walter Duhalde por su uso ${ }^{64}$. La publicidad estuvo a tono con la línea estratégica del FRAP y buscó mostrar las bondades de un programa de reformas profundas. De este modo se pensaba atraer a los sectores medios y al empresariado nacional a un proyecto común con la "clase obrera”. Los lemas de algunos de los afiches son esclarecedores al respecto:

\footnotetext{
${ }^{60}$ Fernández Abara et al34

${ }^{61}$ Véase El Siglo [Santiago], especialmente las declaraciones realizadas por Galvarino Melo en el mes de septiembre de 1957.

${ }^{62}$ "Llamamiento comunista debilita confianza popular en el triunfo”. Boletín del Comité Central del PS 7, [Santiago] Septiembre-Octubre de 1957: 7

${ }^{63}$ Ahora Si [Santiago] 2 de mayo de 1958

${ }^{64}$ Puccio 80
} 
Sí, soy un hombre de clase media...Pero no soy arribista. Votaré por Allende ${ }^{65}$. Soy hombre de empresa. Sí, pero no acepto la expoliación del banco, el trust y el monopolio, ni una política para hambrear ni explotar al pueblo. Votaré por Allende ${ }^{66}$.

La candidatura de Allende también adquirió un fuerte énfasis pedagógico, debiendo encargarse de reenseñar a votar a los adherentes. Este afán adquiría una importancia especial en dicha elección, debido a que era la primera con el nuevo procedimiento de la "cédula única ${ }^{67}$.

De manera casi constante, las campañas contrarias calificaron a Allende de "pije", enrostrándole sus hábitos de vida burgueses, especialmente en el vestir. Estas acusaciones llegaron al paroxismo cuando la prensa de derecha comenzó a difundir informaciones que hacían alusión a que Allende tendría un yate de lujo en la marina de Algarrobo. Para contrarrestar estas aseveraciones, y ridiculizar a sus adversarios, la candidatura de Allende llevó a una concentración en Santiago el supuesto "yate” del candidato, que resultó ser un pequeño bote a remos ${ }^{68}$.

Como himno de la campaña se adaptó la melodía de la canción principal de una popular película de guerra de esos días, "El puente sobre el Río Kwai”, a la que se superpuso una letra alusiva a la campaña: "Pronto la reacción sabrá, cuándo termina su reinar, cuando el doctor Allende a La Moneda llegue a gobernar" ${ }^{169}$.

El candidato recorrió el país en diversas giras. El punto cúlmine de estas tuvo lugar en agosto de 1958, pocos días antes de la finalización de la campaña, cuando se organizó el "tren de la victoria". Este era un tren de cuatro carros, "adornado con un enorme retrato del candidato, con banderas y palmas" Durante once días, el tren recorrió las líneas férreas de la zona central y sur entre Santiago y Puerto Montt, deteniéndose en ciudades y pueblos e introduciéndose en los "ramales" ferroviarios para llegar a localidades apartadas.

Durante sus giras, Allende iba acompañado por los dirigentes de los partidos del FRAP y de las agrupaciones que se sumaron a su campaña. Las concentraciones que se generaban a su arribo se transformaban en una oportunidad para que los adherentes locales

\footnotetext{
${ }^{65}$ Clarín [Santiago] 2 de septiembre de 1958

${ }^{66}$ Ahora Si [Santiago] 19 de agosto de 1958

${ }^{67}$ Sobre la labor de capacitación realizada a militantes y adherentes para adaptarse a los nuevos procedimientos electorales, véase "Instrucciones electorales. Aplicación de la nueva Ley General de Elecciones”. Boletín del Comité Central del PS 2 [Santiago] septiembre-octubre de 1957: 4-6. Informaciones similares pueden encontrarse en Ahora Si, Santiago, 2 de septiembre de 1958. Ya con anterioridad, los militantes de los Partidos del FRAP se encargaban de educar a sus adherentes en procedimientos que les permitieran eludir las disposiciones de la Ley de Defensa Permanente de la Democracia y reinscribir los ciudadanos borrados de los registros electorales a raíz de dicha ley. Sobre el tema véase "Procedimientos para reinscribir a los borrados de los registros electorales”.Boletín del Comité Central del PS 2 [Santiago] septiembre-octubre de 1957: 8.

${ }^{68}$ Ozren Agnic, Allende. El hombre y el político. Memorias de un secretario privado (Santiago: RIL, 2008) 47 48

${ }^{69}$ Suárez 53 y "A la búsqueda de una alianza entre proletarios y burgueses (1933-1958)”, “Allende. 100 Miradas”, La Nación[ Santiago] 30 de junio de 2008.

${ }^{70}$ Clarín [Santiago] 23 de agosto de 1958.
} 
conocieran al candidato, al mismo tiempo que eran la ocasión para que estos últimos pronunciaran sus discursos y se dieran a conocer ante los dirigentes nacionales. En estas ocasiones, quedaba en evidencia la gran popularidad de Allende. La adhesión que generaba era en gran parte derivada de su carisma personal. El candidato era conciente de esa situación y la utilizaba, intentando seducir a sus espectadores en los discursos. Sin embargo, siempre mostró un empecinado rechazo a derivar en un liderazgo mesiánico, algunas veces al costo de hacer actos impopulares. Al respecto, Osvaldo Puccio recordaba una situación acaecida en una concentración en Curicó, cuando una mujer campesina "se acercó y le besó la bastilla del pantalón. Allende al darse cuenta, reaccionó violentamente y le dijo que no debía hacerlo”. Tras lo cual dijo a sus acompañantes:

Compañeros, yo no soy un mesías ni quiero serlo. Yo quiero aparecer ante mi pueblo, ante mi gente, como una posibilidad política. Quiero aparecer como un puente al socialismo. Tenemos la responsabilidad de que eso no vuelva a ocurrir ${ }^{71}$.

El cuatro de septiembre tuvo lugar la elección. Los resultados fueron muy estrechos, produciéndose una gran tensión, a la que se sumó el hecho que ese día tuvo lugar un sismo en Santiago. Allende obtuvo en la elección 356.493 preferencias, es decir, el 28,85\%, quedando en un segundo lugar detrás de Jorge Alessandri, quien obtuvo 389.909 votos alcanzando un $31,52 \%$.

Lo estrecho del triunfo alessandrista, llevó a que muchos elementos del FRAP pensaran en desconocer el triunfo. Especialmente en las bases y en sectores juveniles se quiso llevar adelante una estrategia de movilización social. Esto debido a que se pensaba que el porcentaje que dio la victoria a Alessandri podía explicarse por el fraude electoral y por la acción del "Cura de Catapilco", a quien se acusó de ser un agente comprado por el alessandrismo para "robar" el triunfo de Allende ${ }^{72}$. Ante esta situación, Allende optó por llamar a la calma y a no salirse del cauce legal, esperando que los partidos tomaran una decisión. Esta se hizo pública el 13 de septiembre, cuando el FRAP, por boca del Secretario General del Partido Socialista, Salomón Corbalán, llamó a que los parlamentarios, en la votación del Congreso Pleno, dirimieran la elección como un "plebiscito", entre "izquierda o derecha”. Pese a este llamado, todos los partidos centristas optaron por la línea de mantener la tradición de asignar el triunfo a la primera mayoría relativa. De este modo, Alessandri triunfó en el Congreso Pleno por 147 votos, contra 26 de Allende y 14 en blanco ${ }^{73}$.

\footnotetext{
${ }^{71}$ Puccio 72

${ }^{72}$ Más recientemente, Ozren Agnic ha llegado a sostener que la noche del cuatro de septiembre, Allende habría recibido una invitación a sumarse a un golpe de estado propiciado por militares ibañistas que se negaban a reconocer el triunfo de la derecha. Fuera de Agnic no existen más testigos vivos ni testimonios de dicha reunión. Agnic 59-64

${ }^{73}$ Arancibia 296-297
} 


\section{ANÁLISIS ELECTORAL ${ }^{74}$}

El desempeño electoral de la candidatura de Salvador Allende en las elecciones de 1958 puede analizarse desde distintas perspectivas. En este caso, hemos optado por presentar sus resultados generales a nivel nacional, su distribución según género, clase social y territorio; para, finalmente, centrarnos en la relación de la votación de Allende con la de los partidos políticos que lo apoyaban. Todo esto lo haremos manteniendo una perspectiva comparativa entre las elecciones de 1952 y 1958, con el fin de analizar las transformaciones vividas por el electorado allendista.

En 1952, Salvador Allende había logrado alcanzar 51.980 sufragios, que representaban el 5,43\% de los votos, ubicándose último entre cuatro candidatos. El enorme arrastre de la candidatura ibañista, producido en medio de un rápido deterioro del radicalismo, y la carencia de una plataforma partidaria sólida condicionaron este resultado que, de todos modos, fue útil para construir el liderazgo de Allende en la izquierda chilena ${ }^{75}$. En 1958, la situación electoral cambió sustancialmente. En esa ocasión, Allende captó 356.493 preferencias, es decir, el 28,85\%, inmediatamente detrás del vencedor de la elección, el abanderado de la derecha Jorge Alessandri Rodríguez.

Si analizamos los resultados electorales de Salvador Allende por género, podemos darnos cuenta que en la elección de 1958 existe una diferencia sustancial en el apoyo conseguido entre el electorado femenino y masculino. Allende tendió a ser más exitoso entre el electorado masculino. De hecho, en las elecciones que estamos estudiando alcanzó la primera mayoría relativa entre los hombres ${ }^{76}$.

\footnotetext{
${ }^{74}$ Todos los cuadros estadísticos expuestos en este artículo fueron confeccionados con datos provenientes del Servicio de Registro Electoral para las elecciones presidenciales de 1952 y 1958. desagregadas por género, provincia y comuna.

${ }_{75}$ También es necesario tener en cuenta que las elecciones de 1952 fueron las primeras elecciones presidenciales en que votaron las mujeres en la historia de Chile. Si bien Carlos Ibáñez triunfó tanto entre el electorado femenino como el masculino, la brecha entre Carlos Ibáñez del Campo y Arturo Matte Larraín, primera y segunda mayoría en la elección respectivamente, fue mayor entre los hombres que entre las mujeres. Además, las mujeres sufragaron en menor proporción que los hombres, alcanzando apenas un 30,1\% de los votantes. Por estos motivos no puede sostenerse que Ibáñez haya ganado la elección gracias al voto femenino. Sin embargo, es interesante destacar como importantes sectores del electorado femenino que se estaban incorporando a la vida electoral y que podrían haber sido votantes de la izquierda fueron movilizadas por el ibañismo. En este sentido, un rol importante fue cumplido por las agrupaciones políticas femeninas que apoyaron a Ibáñez en dicha campaña, como el Partido Femenino dirigido por María de la Cruz y el Partido Progresista Femenino dirigido por la doctora María Hamuy, que alcanzaron altos niveles de notoriedad pública. Véase Joaquín Fernández Abara. El ibañismo (1937-1952): Un caso de populismo en la política chilena (Santiago: Ediciones del Instituto de Historia de la Pontifica Universidad Católica de chile, 2007) 174-180 y 213-214.

${ }^{76}$ Véase Sandra Powell, "Political Change in the Chilean Electorate 1952 - 1964". The Western Political Quarterly 23. 2 (1970) 381. También véase Margaret Power, "The Engendering of Anticommunism and Fear in Chile’s 1964 Presidential Election”. Diplomatic History 32.5 (2008) 931 - 953
} 
CUADRO 1

PORCENTAJE DE VOTACIÓN ALCANZADO POR LAS CANDIDATURAS DE SALVADOR ALLENDE EN LOS COMICIOS PRESIDENCIALES DE 1952,Y 1958 EN LOS ELECTORADOS MASCULINO Y FEMENINO.

\begin{tabular}{|l|l|l|}
\hline & Hombres & Mujeres \\
\hline $\mathbf{1 9 5 2}$ & 5,8 & 4,8 \\
\hline $\mathbf{1 9 5 8}$ & 32,38 & 22,34 \\
\hline
\end{tabular}

El apoyo femenino a la derecha, por otro lado, fue palmario entre las mujeres de clase media y clase alta. Este componente social, por cierto, también estuvo presente entre los hombres. A lo largo del período estudiado, el electorado femenino se expandió. En 1952 votaron 287.794 mujeres, equivalentes al 30,1\% de la población electoral. En 1958 ese porcentaje subió a $35 \%$. Sin embargo, este proceso de crecimiento del electorado femenino no vino acompañado de un incremento sustantivo en las cifras relativas de apoyo femenino a Allende, por el contrario la brecha de género en contra de Allende se hizo más patente a pesar de la masificación social y deselitización que conllevaba. Aún así, en comunas de Santiago con mayor predominancia de la clase trabajadora, Allende logró un mayor apoyo que en comunas de las clases media y alta. Es decir existe un componente social de clase en las preferencias del electorado femenino, a pesar de que en términos generales los resultados hayan sido adversos a la izquierda.

CUADRO 2

VOTACIÓN PORCENTUAL FEMENINA DE LAS CANDIDATURAS DE SALVADOR ALLENDE EN LAS ELECCIONES PRESIDENCIALES DE 1952 Y 1958 EN COMUNAS SELECCIONADAS SEGÚN CLASE SOCIAL ${ }^{78}$

\begin{tabular}{|c|c|c|}
\hline & 1952 & 1958 \\
\hline \multicolumn{3}{|l|}{ Clase trabajadora } \\
\hline Barrancas & 8,56 & 33,1 \\
\hline Conchalí & 8,23 & 31,69 \\
\hline Renca & 9,42 & 33,18 \\
\hline Quinta Normal & 8,87 & 31,78 \\
\hline La Cisterna & 6,72 & 27,78 \\
\hline La Granja & 5,11 & 30,11 \\
\hline \multicolumn{3}{|l|}{ Clase media } \\
\hline Ñuña & 5,09 & 15,83 \\
\hline Clase alta & & \\
\hline
\end{tabular}

\footnotetext{
${ }^{77}$ Marcela González, “Te hablo a ti, mujer: madre, esposa y dueña de casa'. La mujer en las campañas presidenciales de 1964 y 1970”. Dimensión Histórica de Chile 13 - 14 (1997 - 1998) 189.

${ }^{78}$ Hemos usado el modelo de comunas representativas según clase social presente en el trabajo de María Elisa Fernández, "Integración de la mujer en política: la mujer chilena en las elecciones presidenciales y el gobierno de Carlos Ibáñez del Campo, 1952-1958”, Cuadernos de Historia 22 (2002)
} 


\begin{tabular}{|l|l|l|}
\hline Providencia & 2,6 & 8,57 \\
\hline Las Condes & 7,9 & 11,75 \\
\hline
\end{tabular}

A pesar de esto, es posible advertir que, electoralmente, Allende fue favorecido por los sectores populares urbanos ${ }^{79}$. En ese sentido, es posible establecer empíricamente una relación entre opción política y clase social, correspondiendo sus expresiones más decididas a los sectores dominantes de la sociedad, verificándose una adhesión cada vez mayor a las propuestas de cambio social mientras más bajo es el estrato social en cuestión, al menos en cuanto al electorado urbano se refiere. Así, Allende, como político y candidato, generaba un mayor rechazo mientras más alto era el sector social de votantes que analizamos. El apoyo electoral de Allende entre las comunas con predominancia trabajadora fue superior al promedio nacional, mientras que en los sectores medios y altos tendió a ser menor a esa cifra. Ello evidencia una tendencia a largo plazo de arraigo popular de las candidaturas de Allende y de aversión relativa por parte de sectores sociales más acomodados.

Cuadro 3

VOTACIÓN PORCENTUAL TOTAL DE LAS CANDIDATURAS DE SALVADOR ALLENDE EN LAS ELECCIONES PRESIDENCIALES DE 1952 Y 1958, EN COMUNAS SELECCIONADAS SEGÚN CLASE SOCIAL.

\begin{tabular}{|c|c|c|}
\hline & 1952 & 1958 \\
\hline \multicolumn{3}{|c|}{ Clase trabajadora } \\
\hline Barrancas & 8,62 & 37,31 \\
\hline Conchalí & 8,17 & 36,81 \\
\hline Renca & 9,96 & 38,36 \\
\hline Quinta Normal & 9,58 & 36,95 \\
\hline La Cisterna & 7,86 & 31,58 \\
\hline La Granja & 5,62 & 35,6 \\
\hline \multicolumn{3}{|l|}{ Clase media } \\
\hline Ñuñoa & 5,87 & 20,52 \\
\hline \multicolumn{3}{|l|}{ Clase alta } \\
\hline Providencia & 3,29 & 12,33 \\
\hline Las Condes & 7,36 & 18,34 \\
\hline
\end{tabular}

Si nos centramos en la distribución territorial de la votación allendista, es posible advertir las zonas geográficas donde el abanderado de la izquierda logró un mejor desempeño. Entre ellas destacan las provincias de Tarapacá, Antofagasta, Atacama, Coquimbo, Arauco y Magallanes. Ello por varios motivos. En primer lugar, es evidente la fuerza del allendismo en las regiones predominantemente mineras. Allende obtuvo marcadas

\footnotetext{
${ }^{79}$ Veáse Maurice Zeitlin y James Petras, “The Working-Class vote in Chile: Christian Democracy vs. Marxism”, en The British Journal of sociology 21. 1 (marzo de 1970) 16 - 29
} 
mayorías en las provincias donde se desarrollaba la gran minería del cobre, la explotación salitrera, la mediana y pequeña minería metálica y la extracción carbonífera. Estas regiones, además, contaban con centros urbanos relevantes, estableciéndose una cierta relación entre urbanización y apoyo electoral para el candidato de la izquierda. En todo caso, en los más importantes centros urbanos del país, como eran Santiago y Valparaíso, Allende, aunque obtuvo altas votaciones, no pudo lograr la primera mayoría, en virtud de la complejidad y diversificación socioeconómica y política de esas urbes. La excepción a esta última situación fue la ciudad de Concepción, donde Allende obtuvo la primera preferencia electoral de una manera bastante pronunciada. Esta última situación es reflejo de un problema de mayor complejidad, que no es explicable exclusivamente por variables socioeconómicas. Nos referimos a la existencia de identidades político-regionales, algunas de ellas capaces de perdurar hasta nuestros días. Los casos más importantes son Tarapacá, Arauco, Concepción y Magallanes. En el primer caso, se trata de la cuna del socialismo pre-soviético y del comunismo chileno, región en la cual el Partido Comunista tuvo un apoyo relevante desde la década de 1930. Un caso similar es el de Arauco, con una gran presencia comunista, debida a la capacidad demostrada por este partido para organizar el descontento social generado por las difíciles condiciones laborales de los mineros del carbón ${ }^{80}$. Concepción y Magallanes fueron tradicionalmente bastiones del socialismo. Los partidos de la izquierda política chilena fueron especialmente populares en dichas zonas, entre otros motivos, por su capacidad de dar conducción al descontento regionalista de larga data en aquellas zonas, incorporándolo a organizaciones políticas de carácter nacional y por la habilidad demostrada en la construcción de redes de apoyo y liderazgos locales, caracterizados por el ejercicio del clientelismo. En estos últimos casos, la izquierda, y en especial el Partido Socialista recibió los réditos derivados de la decadencia del radicalismo constatada desde los inicios de la década de $1950^{81}$.

Por el contrario, Allende tuvo malos desempeños en las provincias agrarias del valle central, sobre todo en aquellas que no contaban con centros urbanos relevantes en su interior. El carácter eminentemente conservador de dichas zonas estuvo dado por el predominio del sector latifundista en la sociedad rural, marcado por el caciquismo y las relaciones personales de dependencia de los trabajadores rurales hacia el sector patronal. Esto explica el que, a pesar de las reformas electorales que tuvieron lugar el año de la elección, las que instauraron la cédula única de votación, volviendo inviables los mecanismos de control sobre la votación de los trabajadores rurales- el desempeño de las candidaturas de Allende fuera inferior al de la derecha y que el apoyo relativo de Allende en dichas provincias fuese menor al promedio nacional.

\footnotetext{
${ }^{80}$ A tal punto que el PC obtuvo en las elecciones municipales de 1947 un $81,69 \%$ de los votos en Lota y un 68,11\% de los votos en Coronel. Huneuss 112

${ }^{81}$ Paul Drake, Socialismo y populismo en Chile (Valparaíso: Universidad Católica de Valparaíso, 1992) 18-19
} 
CUADRO 4

VOTACIÓN PORCENTUAL TOTAL DE LAS CANDIDATURAS DE SALVADOR ALLENDE EN LAS ELECCIONES PRESIDENCIALES DE 1952 Y 1958 EN PROVINCIAS SELECCIONADAS.

\begin{tabular}{|l|l|l|}
\hline & $\mathbf{1 9 5 2}$ & $\mathbf{1 9 5 8}$ \\
\hline Tarapacá & 9,06 & 38,22 \\
\hline Antofagasta & 10,28 & 43,17 \\
\hline Atacama & 4,37 & 34,22 \\
\hline Coquimbo & 5,96 & 32,83 \\
\hline Concepción & 8,7 & 40,43 \\
\hline Arauco & 15,62 & 47,58 \\
\hline Magallanes & 5,59 & 47,78 \\
\hline \multicolumn{3}{|l|}{} \\
\hline Colchagua & 2,57 & 21,87 \\
\hline Maule & 1,63 & 15,63 \\
\hline Linares & 1,88 & 23,85 \\
\hline Malleco & 2,26 & 26,13 \\
\hline Cautín & 0,75 & 21,03 \\
\hline Llanquihue & 0,46 & 18,12 \\
\hline
\end{tabular}

De las cifras puede notarse como comenzó a conformarse una corriente que la opinión pública (citar prensa de la época en que se uso el término) de entonces denominó "allendismo". Así lo hizo notar un reportaje de la revista Ercilla inmediatamente posterior a la elección, el que planteó que "con el nombre que se le quiera dar, la influencia del allendismo en los medios obreros y campesinos es el suceso más importante en profundidad y repercusión de los comicios del 4 de septiembre" ${ }^{\natural 2}$.

En efecto, Salvador Allende logró generar una adhesión política personal, que rebasaba la capacidad de atracción de los partidos de izquierda marxista que lo apoyaban. En las elecciones de 1958 Salvador Allende logró captar un porcentaje de votos visiblemente superior al que habían obtenido los partidos del FRAP en las elecciones de diputados inmediatamente anteriores y siguientes. Allende generó un liderazgo carismático, en el que influían sus dotes de orador, su trayectoria política y su capacidad de aunar a distintas sensibilidades de la centroizquierda en pos de un proyecto de reformismo avanzado. Sus credenciales republicanas y liberal democráticas, facilitaron su llegada al electorado radical. Por otra parte, su discurso nacional-popular que apelaba a la integración de los sectores populares a un relato de historia patria, y su flexibilidad ideológica, poco usual en la dirigencia de los partidos de la izquierda chilena de ese entonces, le permitió captar a sectores independientes e incluso algunos derivados del ibañismo.

\footnotetext{
${ }^{82}$ Ercilla [Santiago] 10 de septiembre de 1958.
} 
CUADRO 5

VOTACIÓN PORCENTUAL DEL FRAP EN LAS ELECCIONES PARLAMENTARIAS DE 1957 Y DE 1961 Y DE SALVADOR ALLENDE EN LAS PRESIDENCIALES DE 1958.

\begin{tabular}{|l|l|l|l|}
\hline & 1957 & 1958 & 1961 \\
\hline FRAP & 22,47 & & 22,59 \\
\hline Allende & & 28,85 & \\
\hline
\end{tabular}

\section{Consideraciones finales}

A través de este estudio, hemos indagado en las relaciones establecidas entre Salvador Allende y los partidos del Frente de Acción Popular en el marco de la elección de 1958. El análisis de los resultados electorales deja en evidencia la capacidad de Salvador Allende de generar una adhesión superior a la de los partidos políticos que lo apoyaban. En este sentido, podemos hablar de la existencia del Allendismo como una fuerza política capaz de movilizar a sectores del electorado que si bien tenían características similares, eran mayores que los de los partidos comunista y socialista. Esta capacidad se explica, en parte por la existencia de segmentos del electorado políticamente disponibles producto de la crisis vivida por el radicalismo y la decadencia del ibañismo. El discurso político de Allende, institucionalista y proclive al acercamiento al centro, a contrapelo de las corrientes predominantes en su propio partido, a la vez que teñido de ciertos rasgos nacionalistas, podía volverse atractivo para los votantes en dispersión del radicalismo y del ibañismo, respectivamente. Por lo demás, las formas en las que se organizó el proceso de elección del candidato y posteriormente el modo en que se abordó la propaganda electoral, reflejan el afán de cooptar esas fuerzas políticas disgregadas. En todo caso, la cercanía del discurso allendista con las líneas estratégicas comunistas, pese su militancia socialista, lo transformaron en un articulador entre los principales partidos del FRAP.

El proceso decisional de los partidos políticos al momento de escoger el candidato también evidencia el arrastre de Allende al interior de los partidos que componían la izquierda. La directiva socialista apoyó su candidatura, pese a no representar su línea política. Al mismo tiempo, la actitud de las bases comunistas reflejaba el arraigo de Allende por sobre la estrategia más cauta de las dirigencias. La rápida elección de Allende en la Convención del Pueblo, que contravenía la estrategia de alargar el evento para que los candidatos menores tuvieran una oportunidad simbólica de competir, refleja la capacidad del candidato de generar lealtades suprapartidistas en las militancias comunista y socialista. De todas maneras, el liderazgo de Allende, con evidentes rasgos carismáticos, no devino en un estilo político personalista. Es más, en sus intervenciones públicas durante la campaña y en la simbología que las rodeaba, Allende hizo un esfuerzo activo y consciente por evitar dicha situación, destacando la importancia de los partidos e instituciones.

Recibido: 8 enero 2015

Aceptado: 12 marzo 2015 


\section{Bibliografía}

\section{Fuentes Primarias}

\subsection{Archivos}

- CIDOC -Universidad Finis Terrae

- Servicio del Registro Electoral

\subsection{Fuentes Hemerográficas}

- Ahora si [Santiagol 1958.

- Boletín del Comité Central del PS [Santiago] 1957-1958.

- Clarín [Santiago] 1958.

- El Siglo [Santiago] 1957-1958.

- Ercilla [Santiago] 1957-1958.

- Principios [Santiago] 1953-1958

- Vea [Santiago] 1957-1958.

\subsection{Compilaciones de fuentes, memorias y entrevistas testimoniales y folletos}

- Agnic, Ozren. Allende. El hombre y el político. Memorias de un secretario privado. Santiago: RIL, 2008.

- Ampuero, Raúl. La izquierda en punto muerto. Santiago: Orbe, 1969.

- Corbalán González, Salomón Partido Socialista. Santiago: La Academia de las Escuelas de Ciencias Políticas de las Universidades de Chile y de Concepción, 1957.

- Fernández Abara, Joaquín; Álvaro Góngora Escobedo y Patricia Arancibia Clavel, Ricardo Núñez. Trayectoria de un socialista de nuestros tiempos. Santiago: Ediciones Universidad Finis Terrae, 2013.

- Hernández Parker, Luis. Señores auditores: muy buenas tardes. Selección de Pamela Hernández y Silvia Hernández. Santiago: Lom Ediciones, 2010.

- Olavarría Bravo, Arturo. Chile entre dos Alessandri. Memorias Políticas. Tomo II, Santiago: Editorial Nascimento, 1962.

- Puccio, Osvaldo. Un cuarto de Siglo con Allende. Recuerdos de su secretario privado. Santiago: Emisión, 1985.

- Schnake, Erich. Un socialista con historia. Memorias. Santiago: Aguilar, 2004.

- Suárez Bastías, Jaime. Allende: visión de un militante. Santiago: Ochoymedio, 2008.

- V.V.A.A. Medidas concretas del Gobierno Popular. Santiago: Imprenta Lautaro, 1958. 
- Waiss, Oscar. Nacionalismo y Socialismo en América Latina. Santiago: Prensa Latinoamericana, 1954.

\subsection{Diccionarios Biográficos}

- De Ramón, Armando. Biografías de chilenos: miembros de los poderes Ejecutivo, Legislativo y Judicial (1876-1973). Santiago: Ediciones Universidad Católica de Chile, 2003.

- Empresa Periodística de Chile, Diccionario biográfico de Chile. Duodécima edición. 1962-1964. Santiago: Empresa Periodística de de Chile, 1964.

\section{Fuentes Secundarias}

- Álvarez Vallejos, Rolando. Arriba los pobres del mundo. Cultura e identidad política del Partido Comunista de Chile entre democracia y dictadura. 1965-1990. Santiago: Lom, 2011.

- Amorós, Mario. Allende. La Biografía. Santiago: Ediciones B, 2013.

- Antúnez, Catalina. A usted lo necesito! La campaña presidencial de Jorge Alessandri Rodríguez en 1958. Tesis para optar al grado de Licenciada en Historia. Santiago: Universidad Alberto Hurtado, 2009.

- Arancibia, Patricia. "La elección presidencial de 1958. Jorge Alessandri y la derecha a la Moneda”. San Francisco, Alejandro y Ángel Soto. Camino a la Moneda. Las elecciones presidenciales en la historia de Chile. Santiago: Instituto de Historia de la Pontificia Universidad Católica de Chile y Centro de Estudios Bicentenario. 2005.

- Arrate, Jorge y Eduardo Rojas. Memoria de la Izquierda Chilena. Tomo I (18501970). Santiago: Vergara, 2003.

- Bazdresch, Carlos. "El Pensamiento de Juan F. Noyola”. El trimestre económico 50. 198. 2 (junio de 1983).

- Casals Araya, Marcelo. El Alba de Una Revolución. La Izquierda y el proceso de Construcción Estratégica de la "Vía Chilena al Socialismo". 1956-1970. Santiago: Lom, 2010.

- Cortés, Alexis. "El movimiento de pobladores chilenos y la población La Victoria: ejemplaridad, movimientos sociales y derecho a la ciudad". EURE 40. 119 (enero de 2014).

- Daire, Alonso. Derogación de la Ley de Defensa de la Democracia. Legalidad al comunismo en Chile, 1958. Tesis para optar al grado de Licenciado en Historia. Santiago: Pontificia Universidad Católica de Chile, 1989.

- Drake, Paul. Socialismo y populismo en Chile. Valparaíso: Universidad Católica de Valparaíso, 1992. 
- Etchepare Jensen Jaime. "El advenimiento de Gabriel González Videla al Gobierno y el Fracaso de la Unión Nacional” (1946-1948). Revista de Historia 2 (1992).

- Etchepare Jensen, Jaime. “Ibáñez y su revolución de 1952”, Política 26 (1991).

- Faúndez, Julio. Izquierdas y democracia en Chile, 1932-1973. Santiago: Ediciones Bat, 1992.

- Fernández Abara, Joaquín El ibañismo (1937-1952): Un caso de populismo en la política chilena. Santiago: Ediciones del Instituto de Historia de la Pontifica Universidad Católica de chile, 2007.

- Fernández, María Elisa. "Integración de la mujer en política: la mujer chilena en las elecciones presidenciales y el gobierno de Carlos Ibáñez del Campo, 1952-1958”. Cuadernos de Historia 22 (2002).

- Furci, Carmelo. El Parido Comunista de Chile y la vía al Socialismo. Santiago: Ariadna, 2008.

- Garcés, Mario. Tomando su sitio. El movimiento de pobladores en Santiago, 19571970. Santiago: LOM, 2002.

- González, Marcela. “Te hablo a ti, mujer: madre, esposa y dueña de casa'. La mujer en las campañas presidenciales de 1964 y 1970”. Dimensión Histórica de Chile 13 14 (1997 - 1998).

- Huneeus, Carlos. La Guerra Fría Chilena. Gabriel González Videla y la Ley Maldita. Santiago: Debate, 2008.

- Jobet, Julio Cesar. Historia de Partido Socialista de Chile. Santiago: Ediciones Documentas, 1987.

- Milos, Pedro. Historia y memoria. 2 de abril de 1957. Santiago: Lom-Universidad Alberto Hurtado-2007.

- Moulian, Tomás: El gobierno de Ibáñez: 1952-1958. Santiago: FLACSO, 1986.

- Ortega Martínez, Luis. "Del Frente de Trabajadores al Congreso de Chillán. Los Socialistas de Chile entre 1956 y 1967". Revista Electrónica Palimpsesto 1. 1. (2003).

- Powell, Sandra. "Political Change in the Chilean Electorate 1952 - 1964", The Western Political Quarterly 23. 2 (1970).

- Power, Margaret. "The Engendering of Anticommunism and Fear in Chile's 1964 Presidential Election”, Diplomatic History 32. 5 (2008).

- Riquelme Segovia, Alfredo "La Guerra Fría en Chile: Los intrincados nexos entre lo nacional y lo Global”, Tanya Harmer y Alfredo Riquelme Segovia (Editores), Chile y la Guerra Fría Global. Santiago: Instituto de Historia de la Pontificia Universidad Católica de Chile -RIL Editores, 2014.

- Riveros Romero, Cecilia: Salvador Allende: Un líder para al izquierda chilena. Prólogo para un epílogo. Tesis para optar al Grado de Licenciado en Historia. Santiago: Pontificia Universidad Católica de Chile, 2006.

- Rubio Apiolaza, Pablo. "La izquierda chilena en la década de 1950: Socialistas, comunistas y sus contradicciones”, en Revista Electrónica Palimpsesto 1. 1. (2003). 
- Silva, Patricio. En el nombre de la razón. Tecnócratas y política en Chile. Santiago: Universidad Diego Portales, 2010.

- Simunovic, Pedro: Identidad y antiimperialismo en la izquierda: el caso de la Misión Klein - Saks. Tesis para optar al grado de Licenciado en Historia, Santiago: Universidad Alberto Hurtado, 2013.

- Torres Dujisin, Isabel: La crisis del sistema democrático: Las elecciones presidenciales y los proyectos políticos excluyentes. Chile-1958-1970. Santiago: Centro de Investigaciones Diego Barros Arana - DIBAM - Editorial Universitaria, 2014.

- Urzúa Valenzuela, Germán. Historia política de Chile y su evolución electoral. (Desde 1810 a 1992). Santiago: Editorial Jurídica de Chile, 1992.

- Valenzuela, J. Samuel. "Orígenes y transformaciones del sistema de partidos en Chile”, en Estudios Públicos 58 (1995).

- Veneros, Diana. Allende. Un ensayo psicobiográfico. Santiago: Random House Mondadori, 2003.

- Zeitlin, Maurice y James Petras, "The Working-Class vote in Chile: Christian Democracy vs. Marxism”, en The British Journal of sociology 21. 1 (marzo de 1970) 